\title{
EL DESARROLLO PROFESIONAL DEL PROFESOR DE CIENCIAS MEDIANTE TUTORÍAS DE GRUPOS COOPERATIVOS. ESTUDIO DE OCHO CASOS
}

\author{
FURIÓ, CARLES ${ }^{1}$ y CARNICER, JESÚS ${ }^{2}$ \\ ${ }^{1}$ Departament de Didàctica de les Ciències Experimentals i Socials. Universitat de València \\ ${ }^{2}$ IES de Calamocha. Teruel
}

\begin{abstract}
Resumen. La formación continuada de profesores de ciencias, concebida como desarrollo profesional, ha adquirido recientemente relevancia en la investigación en didáctica de las ciencias. En este artículo se presenta un modelo de formación de profesores en activo basado en un programa teórico-práctico desarrollado mediante tutorías de orientación constructivista. Este modelo se ha puesto a prueba en un estudio longitudinal de varios años en el que se ha hecho un seguimiento del cambio didáctico ocurrido en ocho profesores de ciencias de secundaria. En el trabajo se presenta un diseño pretest-postest con indicadores de los cambios epistemológicos y actitudinales que han tenido lugar en estos profesores al reflexionar y aplicar nuevas estrategias de enseñanza organizados en pequeños equipos cooperativos.
\end{abstract}

Palabras clave. Desarrollo profesional, profesores, tutoría cooperativa, programa, cambio didáctico.

Summary. Continued science teacher education, conceived as professional development, has recently acquired relevance in the research of science education. This paper presents a model of in-service training for teachers based on a theoretical-practical program developed through coaching of a constructivist orientation. This model has been tested in a longitudinal study of some years in which a follow-up of the didactic change taking place in eight high school science teachers has been made. This paper presents a pretest-postets design with indicators of the epistemological, methodological and attitudinal changes that have occurred in these teachers after reflecting on and applying new strategies of teaching organised in small cooperative teams.

Keywords. Professional development, teachers, cooperative coaching, program, didactic change.

\section{INTRODUCCIÓN}

El análisis de las investigaciones sobre formación del profesorado de ciencias presentada por Munby y Russell (1998) en el último International Handbook of Science Education ha puesto de relieve dos aspectos importantes. En primer lugar, se resalta que estas investigaciones han adquirido cierta relevancia como dominio particular dentro de la investigación sobre la formación del profesorado desde fines de la década de los ochenta y, en segundo lugar, que se le está dando más importancia al conocimiento práctico de la enseñanza (Schön, 1992) que a la investigación proceso-producto basada en la comparación de expertos y novatos impulsada por la psicología del procesado de la información.
No obstante, aquellos autores, defensores de una epistemología del conocimiento profesional basada en la acción, acaban su análisis concluyendo que tanto este modelo como el fundado en el constructo conocimiento base para enseñar son bastante incompletos porque dejan un gran número de problemas sin resolver. Así pues, una asignatura pendiente es la búsqueda de modelos de formación del profesorado de ciencias que sean consistentes con los resultados de investigación y eficaces para el desarrollo profesional de los docentes. Este desarrollo ha de entenderse como un proceso continuo de integración teoría-práctica en la que el profesor se concibe como aprendiz en tanto que innovador o inves- 
tigador que participa en la construcción de la «ciencia de enseñar ciencia», es decir, en la didáctica de la ciencia (Porlán, 1998; Gil, Carrascosa y Martínez Terrades, 2000). El objetivo principal de este trabajo es proponer un modelo de formación continuada coherente con el marco constructivista que, a título de hipótesis, pueda ponerse a prueba de forma experimental. Este modelo ha de llegar a concretar estrategias que faciliten en los profesores la reestructuración de sus esquemas de acción así como las creencias, los conocimientos y las actitudes subyacentes que los guían (Borko y Putnam, 1996). En concreto, las preguntas que se intentan responder son las siguientes:

- ¿Es posible asimilar el desarrollo profesional docente a una reestructuración o cambio didáctico en el que prime la generación de actitudes positivas hacia la innovación y la investigación didácticas?

- Y, en caso afirmativo, ¿cuáles son las estrategias que se deben priorizar en la formación continuada para que se favorezca el cambio didáctico?

Una vez caracterizadas las estrategias de los nuevos modelos de formación continuada, se pondrán a prueba mediante el diseño del oportuno programa base de formación y su implementación a grupos pequeños de profesores para contestar: ¿Cuáles son los resultados alcanzados respecto a los cambios esperados en la epistemología personal docente -incluidas las actitudes- y la práctica educativa?

\section{EL DESARROLLO PROFESIONAL DE LOS PROFESORES DE CIENCIA COMO CAM- BIO CONCEPTUAL, EPISTEMOLÓGICO,ME- TODOLÓGICO Y ACTITUDINAL}

Desde un marco constructivista, el desarrollo profesional del profesorado se puede concebir como una reestructuración de las creencias, las actitudes y los comportamientos del profesorado sobre la ciencia y la educación científica (cambio didáctico). La investigación ha puesto de relieve la existencia de una epistemología personal docente construida a través de la experiencia, primero como alumno y después como profesor, que mediatiza las actitudes y los comportamientos que presenta el docente en clase. Esta epistemología personal docente puede ser un obstáculo al cambio didáctico pero también ha de considerarse el punto de partida para nuevas construcciones didácticas (Tobin y Espinet, 1989; Carretero y Limón, 1996).

Los cambios a lograr en la epistemología personal y en la práctica del profesor no son sencillos. Se han de proponer estrategias que faciliten cambios conceptuales respecto al modelo de enseñanza que practica el profesor, cambios metodológicos en su saber hacer práctico y, en particular, que logren cambios actitudinales positivos hacia la didáctica de las ciencias. Esta reestructuración del pensamiento docente ha de ser producida conscien- temente por el propio profesor y puede ser contraproducente plantearla como conflicto cognitivo explícito entre lo que piensa y hace el profesor y lo que está mostrando la investigación didáctica. Como indica Bell, (1998) este cambio didáctico tiene que ser percibido como un triple desarrollo profesional, social y personal del propio profesor que busca mejorar sus enseñanzas y conseguir así un mejor aprendizaje en sus estudiantes. Se considera al profesor como sujeto en formación actitudinal que no sólo tiene creencias sobre la ciencia y la educación científica, sino también actitudes no muy positivas hacia la investigación e innovación didácticas, que se pretenden cambiar en el programa de formación.

En este sentido, un programa de formación continuada ha de intentar conseguir, como mínimo, un cambio actitudinal en el profesorado hacia la didáctica de las ciencias, entendida como núcleo vertebrador de la formación docente. Es por ello que la finalidad primordial de esta formación es convertir al profesor en un innovador y, si es posible, iniciarle en la investigación didáctica. Kyle y otros (1991), al comentar el papel de la investigación educativa en la enseñanza, resaltan que: «Una nueva imagen del rol del profesor está emergiendo. Además de poseer un conocimiento específico de la disciplina y un conocimiento sobre didáctica específica, los enseñantes han de disponer de tiempo para debatir ideas con sus colegas, participar en su desarrollo profesional e investigar sobre la enseñanza y el aprendizaje.» Los profesores con su epistemología personal, de entrada, han de apropiarse de manera significativa del conocimiento didáctico existente y para ello han de implicarse en la reconstrucción de este conocimiento. Así pues, un modelo de formación coherente con estos planteamientos constructivistas utilizará la metáfora de los profesores (en formación inicial o continuada) como investigadores noveles que trabajan en equipos replicando investigaciones didácticas dirigidos, en una fase inicial, por un investigador experto (el tutor, asesor o coordinador) en aquellas investigaciones (Furió, 1994a; Furió y Gil, 1999). Esta primera fase de interregulación requerirá tiempo, pero, una vez conseguido el cambio actitudinal, el grupo de profesores podrá pasar de ser «consumidor» a «productor» de investigación $\mathrm{y}$, por tanto, podrá funcionar como equipo de investigación que autorregula su funcionamiento al igual que sucede al final de cualquier proceso de formación de investigadores en un dominio científico.

La hipótesis de trabajo subyacente en este modelo de formación basado en la «enseñanza como investigación orientada» se puede formular de la siguiente manera:

«Sólo si se fomenta y logra crear en el profesor o, mejor aún, en el equipo de profesores una actitud investigativa hacia los problemas del aula, se conseguirá el cambio epistemológico, se mejorarán sus enseñanzas (cambio metodológico) y también aumentarán sus expectativas de desarrollo profesional.»

Ahora bien, el cambio didáctico que pueda operarse en el profesor va a depender fundamentalmente de la epistemología personal docente al iniciarse el programa de 
formación y, también, de las características concretas del programa que se vaya a llevar a la práctica. Estas dos variables habrán de tenerse en cuenta a la hora de operativizar la hipótesis y elaborar diseños para ponerla a prueba de forma experimental.

\section{ESTRATEGIAS OUE, A TÍTULO DE HIPÓ- TESIS, HAN DE PRIORIZAR LOS NUEVOS MODELOS DE FORMACION CONTINUADA}

Las estrategias de los nuevos modelos de formación han de facilitar el cambio conceptual, epistemológico, metodológico y actitudinal en el profesorado de ciencias hacia enseñanzas innovadoras que, en nuestro caso, van a concretarse en la enseñanza-aprendizaje como investigación orientada (Gil, 1993; Furió, 1994b). Para llevar a cabo estas nuevas estrategias será imprescindible la ayuda de un tutor experto en la innovación que desea ponerse a disposición de los profesores. Las características de los nuevos modelos de formación han de ser coherentes con las orientaciones constructivistas y, entre otras posibles, se destacan las que se han considerado en la hipótesis:

a) Los nuevos modelos de formación docente han de tener en cuenta las ideas, intereses y necesidades formativas de los profesores que participan en el mismo.

b) Han de tener como primer objetivo la (re)construcción de los conocimientos didácticos y, en particular, mostrar la existencia de alternativas didácticas eficaces al modelo de enseñanza por transmisión de conocimientos ya elaborados.

c) Otro rasgo característico de los nuevos modelos de formación docente es que han de favorecer la reflexión colectiva de los profesores en pequeños grupos sobre los problemas y dificultades que se presentan en el aprendizaje habitual. El tratamiento de estas situaciones problemáticas didácticas pondrán en cuestión el pensamiento docente espontáneo sobre la ciencia, la enseñanza y el aprendizaje de las ciencias (Gil et al., 1991).

d) Al tiempo que se favorece un debate crítico sobre la enseñanza convencional, se facilitarán otras posibilidades innovadoras de enseñanza más eficaces basadas en los avances de la didáctica de las ciencias. Aquí se necesitará prever la aportación de ayuda externa al grupo de profesores mediante un investigador experto en aquellas innovaciones que actuará como tutor de los equipos de trabajo y cuyo papel fundamental será el de facilitar la interregulación de la tarea en los equipos docentes.

$e$ ) En este período de interregulación se han de favorecer vivencias en clase de las propuestas innovadoras en las que se pueda valorar, por el propio profesor, su potencialidad en cuanto a las mejoras (cambio) que se pueden conseguir en la docencia habitual. Es decir, se ha de impulsar la integración teoría-práctica al tiempo que se fomentan actitudes positivas en el profesorado hacia la innovación e investigación didácticas. f) Finalmente habrá que idear estructuras dinámicas que favorezcan, a medio y largo plazo, la incorporación de profesores a las tareas de producción de innovación e investigación sobre los problemas de la enseñanza (conexión, integración o colaboración con equipos de profesores universitarios o de secundaria en departamentos o en centros de profesores, creación de redes de investigadores y profesores en asociaciones, etc.).

\section{DISEÑO DE UN PROGRAMA BASE DE TU- TORIAS CONSISTENTE CON LAS CARAC- TERISTICAS DE LOS NUEVOS MODELOS DE FORMACIÓN DOCENTE}

En primer lugar, se presentará, a modo de hipótesis, un programa base de formación a implementar en grupos pequeños de profesores/as con la finalidad de ver si se logra un cambio didáctico apreciable. A continuación, se pasará a presentar la forma de agrupar a los profesores/as en diferentes equipos teniendo en cuenta sus intereses, perfiles profesionales, expectativas, etc., y cómo se adaptó el programa base a los equipos formados. Finalmente se pasará a diseñar instrumentos y criterios que permitan poner a prueba la hipótesis y constatar si se ha producido el cambio esperado.

\section{Estructura del programa base de formación}

Como se ha indicado en el apartado anterior, el programa a diseñar ha de facilitar la reflexión colectiva del profesorado acerca de sus necesidades profesionales y ha de tener flexibilidad para poder adaptarse a los propios intereses particulares del grupo de profesores. Por ello se ha ideado un «programa base» constituido por una serie de módulos desarrollados en forma de programas de actividades a debatir por pequeños grupos de profesores en sesiones semanales de dos o tres horas. En estas sesiones se plantea el tratamiento científico de problemas didácticos $\mathrm{y}$, a ser posible, el programa ha de concluir con el diseño y la puesta en práctica en el aula de alguna innovación concreta basada en la investigación didáctica. La estructura del programa base de formación se basa en las propuestas de nuestro grupo de trabajo (Furió y Gil, 1989; Gil et al., 1991; Gil 1993; Furió y Gil, 1999) y de manera resumida contiene los siguientes módulos:

a) Conocer la materia. Tiene por objeto la revisión de alguno de los contenidos científicos a enseñar y, en particular, se pone el énfasis en la selección de los contenidos que se quieren innovar.

b) Conocer y cuestionar el pensamiento docente espontáneo. Se centrará en el análisis reflexivo sobre visiones deformadas y actuales de la naturaleza de la ciencia y del trabajo científico y en la propuesta genérica de actividades de enseñanza coherentes con una visión más adecuada de los procedimientos de la ciencia. 
c) Aprender conocimientos teóricos sobre cómo aprenden los estudiantes. Se plantea, por una parte, la existencia de las concepciones alternativas de los estudiantes y, por otra, la necesidad de profundizar en los modelos de aprendizaje de las ciencias como cambio conceptual, metodológico y actitudinal.

d) Saber preparar un programa de actividades centrado en la búsqueda de soluciones a situaciones problemáticas didácticas. En este módulo, primero se selecciona y se vivencia un programa de actividades basado en el tratamiento científico de una situación problemática de interés escolar. En una segunda fase, se inicia la elaboración de un programa de actividades.

e) Saber dirigir la actividad de los alumnos/as en clase. Se debate cómo organizar y presentar las actividades a los estudiantes en una clase, así como crear un clima de aula que facilite las interacciones necesarias para enseñar y aprender.

f) Evaluar la actividad de clase y, en particular, de la enseñanza a partir de métodos de observación no participante en el aula. Se prestará particular atención a la evaluación del clima de aula.

g) Iniciar en la realización de innovaciones e investigaciones didácticas hasta llegar, a ser posible, a la elaboración de «productos didácticos».

La flexibilidad prevista en el programa base consiste en abordar con mayor o menor profundidad los contenidos de los módulos que los profesores/as asistentes consideren más interesantes. En todo caso, conviene que el profesorado participe en la selección de su propio programa de formación ante un plan de trabajo provisional que, de entrada, presentará el tutor tras sondear previamente los intereses de los asistentes.

\section{Perfiles de los profesores que participaron en el pro- grama y constitución de los equipos}

El trabajo de las tutorías con los grupos de docentes se extendió a lo largo de tres cursos académicos entre los años 1991-94 durante los cuales se estudiaron ocho casos de formación permanente de profesores de ciencias que participaron en el programa de formación. No todos ellos se incorporaron al mismo tiempo ni en el mismo equipo. El cuadro I resume los cuatro equipos que se organizaron a lo largo del tiempo. En cada equipo se han subrayado el nombre de los ocho profesores que fueron objeto de un seguimiento más exhaustivo. Como puede observarse también participaron otros profesores interesados pero que manifestaron que no iban a aplicar las innovaciones en el aula, al menos a corto plazo.

De estos ocho profesores, cuatro eran noveles (Reme, Chusa, Pepe y Víctor), pues al iniciar el programa se encontraban en período de inducción (sólo tenían dos o tres años de experiencia profesional). Los cuatro restantes tenían una mayor experiencia, que iba desde los seis años de Clara y Josefa, pasando por los once de Jaime, hasta los veintiuno de Ignacio. Todos ellos solicitaron voluntariamente asesoría didáctica del Centro de Profesores/as (CEP) de Teruel en el que Jesús, uno de los autores de este artículo trabajaba como asesor de formación de ciencias experimentales.

La constitución de los equipos en diferentes seminarios se hizo de forma flexible siguiendo algunos criterios generales tales como el interés común de los profesores que iban a formar un grupo, su pertenencia al mismo centro o si el profesor/a era novel o experimentado. Así por ejemplo, el Seminario 1 (Introducción a la Química), se formó con profesores con experiencia docente que habían asistido a cursos sobre aprendizaje por investigación y su objetivo era «aprender a diseñar programas de actividades para la clase de química». El Seminario 2 (Ciencias de la Naturaleza de la ESO) estaba constituido por profesores noveles cuyo interés prioritario era «saber dirigir la actividad de los alumnos/as poniendo en práctica una nueva estrategia metodológica». No obstante, los criterios se adaptaron flexiblemente según las circunstancias; así, por ejemplo, Víctor (novel) formó con Antonio O. (experimentado) el Seminario 3 (Enseñanza de la Química) de $2^{\circ}$ de BUP o en el Seminario 4 (Innovaciones en Ciencias) se agruparon Reme, Chusa, Pepe y Josefa del mismo centro con Víctor y Jaime de centros distintos.

En el primero de los equipos que se constituyó en el curso 1991-92 (Seminario 1) participaron, entre otros, Ignacio (licenciado en física) y Clara (licenciada en química) que trabajaban en el mismo centro y querían experimentar nuevas metodologías en la asignatura de Física y Química de $2^{\circ}$ de BUP (16 años). El Seminario 2 se constituyó por Reme (licenciada en química), Chusa (licenciada en química) y Pepe (licenciado en biología), que trabajaban también juntos en otro centro de Teruel. Estos tres profesores iban a impartir en el curso 1992-93 las Ciencias de la Naturaleza (14-16 años) en la reforma de las EEMM por primera vez. De este mismo centro se incorporó a este grupo, en el curso 1993-94 (Seminario 4), Josefa (licenciada en química), que tenía que impartir la Física y Química de los nuevos bachilleratos (1718 años). También a este último Seminario se adhirió Jaime, que también iba a experimentar por primera vez la asignatura de Ciencias de la Naturaleza, aunque en otro centro de Teruel. Por otra parte, Víctor trabajaba en el instituto de Calamocha, ciudad a $75 \mathrm{~km}$ de Teruel, donde impartía por primera vez Física y Química de $2^{\circ}$ de BUP, intentando poner en práctica una estrategia de trabajo en grupos cooperativos con no demasiado éxito, por lo que solicitó la ayuda del asesor. Este profesor con otro colega del mismo centro formaron el Seminario 3 en el curso 1992-93. Al inicio del curso siguiente, Víctor se incorporó al Seminario 4.

Todos los profesores/as dominaban, de acuerdo con sus titulaciones, los contenidos de las materias que iban a impartir; por lo tanto, se podía partir del supuesto de que habían superado el primer impedimento al cambio didáctico (conocimiento de la materia a enseñar) (Tobin y Espinet, 1989). De entrada, todos presentaban una actitud favorable hacia la puesta en práctica de nuevas 
metodologías, bien por propia iniciativa o porque los centros en los que trabajaban estaban implicados en la reforma de las EEMM. Al menos eso se deducía de sus motivaciones y expectativas manifestadas en la ficha de inscripción y en el primer cuestionario que contestaron al inscribirse en el programa.

\section{Planificación de las tutorías llevadas a cabo con los grupos de profesores}

Cada equipo trabajó sobre la base de un guión presentado por el tutor y consensuado con los diferentes equipos en los cursos 1991-92 y 1992-93. En el curso 1993-94 el guión se elaboró por los propios participantes y el tutor. Los guiones de trabajo de los diferentes seminarios tenía un mismo hilo conductor fundamentado en el programa base y en los posibles intereses de profesores principiantes o con experiencia docente. Estos intereses, en buena lógica, se pueden deducir de la prioridad dada por el profesor a las distintas tareas que normalmente suele realizar al preparar y desarrollar sus clases. En este caso, el hilo conductor se basó en el tratamiento que se puede dar a tres situaciones problemáticas frecuentes en la enseñanza, a saber:

a) En la tutoría que se llevó a cabo en el Seminario 1 se plantea como objetivo fundamental dar respuesta a la cuestión: ¿Cómo diseñar y elaborar programas de actividades de temas concretos de física y química o de ciencias basados en el aprendizaje como investigación orientada? Éstos eran los intereses del profesorado con experiencia que desea diseñar sus propios materiales y que se corresponden con los objetivos del módulo D del programa base. No obstante, al desarrollar estos objetivos, era de esperar que surgiera de forma natural el tratamiento del contenido de otros módulos didácticos como, por ejemplo, secuenciar y organizar los contenidos del tema seleccionado (módulo A) o debatir las principales dificultades de aprendizaje del tema (módulo C).

b) En las tutorías que se desarrollaron en los Seminarios 2 y 3 se priorizaron los intereses del grupo de profesores noveles más preocupados por saber dirigir la actividad de sus alumnos en el aula. El objetivo fundamental a plantear es: ¿Cómo poner en práctica en el aula de ciencias las nuevas estrategias metodológicas coherentes con el aprendizaje por investigación? Esta finalidad se corresponde con la del módulo E del programa base. Pero, previamente, se centraba la reflexión colectiva en aspectos clave de la didáctica de las ciencias, tales como la enseñanza de conceptos científicos, la resolución de problemas y la realización de prácticas de laboratorio (módulo B).

c) Finalmente, la tercera situación problemática trata de buscar soluciones a la cuestión: ¿Cómo diseñar, desarrollar y evaluar pequeñas innovaciones o investigaciones en clase de ciencias? Esta tutoría se organiza después de haber realizado las dos tareas anteriores y permite iniciarse en el diseño y desarrollo de innovaciones o investigaciones (módulos F y G). Los contenidos de la tutoría se centraban en otros aspectos no tratados anteriormente, tales como nuevas formas de organizar el aula, procedimientos para detectar ideas alternativas de los alumnos, evaluación de las actividades propuestas en un programa de clase, etc.

\section{DISEÑO PARA EVALUAR EL CAMBIO EPIS- TEMOLOGICO, METODOLÓGICO Y ACTI- TUDINAL LOGRADO EN LAS TUTORÍAS}

Para constatar el cambio logrado había que conocer en profundidad las ideas y las prácticas de cada uno de los ocho profesores/as en diferentes momentos del desarrollo del programa. Así, pues, se utilizó, preferentemente, una metodología cualitativa para el seguimiento individual y grupal de los casos; metodología que se integraba en la actividad propia de los respectivos seminarios de formación en los que participaron estos profesores y profesoras. Con el fin de aumentar la fiabilidad de los datos a obtener, se utilizó un diseño de aborde múltiple con una diversidad de instrumentos para triangular las fuentes de información y ver si había convergencia en los resultados (Youngman, 1982). Así, por ejemplo, se utilizaron cuestionarios abiertos al comienzo (documento 1 del anexo) y al final del programa (documento 2), entrevistas personales semiestructuradas sobre la base de esos cuestionarios (documento 3), varios instrumentos para observar y valorar la práctica de aula como registros en audio y vídeo de clases, un cuestionario abierto (documento 3 ) y otro cerrado (documento 5). El análisis de los cambios producidos se realizó mediante un diseño pretest-postest aplicado a cada uno de los profesores según el tipo de cambio esperado. Los objetivos perseguidos y los criterios de valoración de cada uno de los instrumentos se irán detallando a continuación según lo vaya requiriendo la exposición del diseño.

\section{Indicadores utilizados para diagnosticar el cambio epistemológico alcanzado}

En lo referente a las ideas sobre la ciencia y su construcción, la investigación sobre la epistemología docente espontánea ha mostrado que los profesores/as presentan visiones empiroinductivistas sobre las construcciones científicas. Según estas ideas, parece que todo conocimiento se inicia mediante una observación sensorial que acaba generalizándose en forma de descubrimiento de una ley. Para llegar a estos descubrimientos se ha de seguir «el método científico» concebido como una serie rígida de etapas que comienza con la observación o experimentación. Esta visión rígida de la actividad científica no imagina la posibilidad de diferentes estrategias o caminos para llegar a las mismas conclusiones y mucho menos vueltas atrás (Gil, 1993; Fernández, 2000).

En el cuadro II se presenta el cambio epistemológico que sobre la actividad científica se espera que logren los profesores participantes en el programa; en particular, después de haber tratado el módulo B. Es decir, se presupone que pasarán de enfatizar visiones empiristas 
Cuadro I

Equipos formados con el profesorado participante en cada curso.

\begin{tabular}{|c|c|c|c|}
\hline CURSO & LUGAR DE CELEBRACIÓN & EQUIPO & PROFESORADO \\
\hline $1991-92$ & CEP de Teruel & $\begin{array}{l}\text { Seminario } 1 \\
\text { «Introducción a la Química» }\end{array}$ & Ignacio, Clara, Miguel y Antonio M. \\
\hline \multirow[t]{3}{*}{$1992-93$} & CEP de Teruel & $\begin{array}{l}\text { Seminario } 1 \\
\text { «Introducción a la Química» } \\
\text { (Continuación) }\end{array}$ & Ignacio, Clara, Miguel y Antonio M. \\
\hline & & $\begin{array}{l}\text { Seminario } 2 \text { «Ciencias de la } \\
\text { Naturaleza de la ESO» }\end{array}$ & $\underline{\text { Reme, Chusa y Pepe }}$ \\
\hline & Extensión de Calamocha & $\begin{array}{l}\text { Seminario } 3 \\
\text { «Enseñanza de la Química } \\
\text { de } 2^{\circ} \text { de BUP» }\end{array}$ & Víctor y Antonio O. \\
\hline $1993-94$ & CEP de Teruel & $\begin{array}{l}\text { Seminario } 4 \\
\text { «Innovación en Ciencias» }\end{array}$ & $\begin{array}{l}\text { Clara, Chusa, Pepe, Víctor, } \\
\underline{\text { Jaime y Josefa }}\end{array}$ \\
\hline
\end{tabular}

y rígidas (rasgos 1 y 2 del cuadro II) a poner el énfasis en visiones hipotéticas y flexibles sobre los procedimientos de la ciencia (rasgos 3 y 4 ).

Para extraer información sobre el pensamiento del profesor acerca de la ciencia y la actividad científica antes de comenzar las tutorías, se elaboraron las preguntas 1 y 6 del cuestionario inicial (documento 1) relativas a la construcción de un diagrama de investigación y a cómo suponían que evoluciona el conocimiento científico a lo largo de la historia, respectivamente. También se ideó una entrevista (documento 3 ) y otros instrumentos que aquí no se han expuesto por no hacer excesivamente extenso el trabajo. En el postest se aplicaron, principalmente, las preguntas 1, 2, 3 y 4 del cuestionario final (documento 2) al grupo experimental de profesores tutorados así como las correspondientes entrevistas para profundizar en las respuestas dadas a las preguntas del

Cuadro II

El cambio epistemológico se analizará a través del énfasis que muestren los profesores al pasar de visiones empiristas y rígidas a visiones hipotéticas y flexibles de la actividad científica.

\begin{tabular}{|c|c|}
\hline Énfasis en concepciones empiristas y rígidas & Énfasis en concepciones hipotéticas y flexibles \\
\hline $\begin{array}{l}\text { 1) Rasgos que se enfatizan en las concepciones empiristas y } \\
\text { ateóricas: } \\
\text { - Se atribuye origen sensorial a los conocimientos científicos. } \\
\text { - Se resalta el papel de la observación neutra como punto de partida } \\
\text { de la investigación. } \\
\text { - Se considera que la realización de experimentos es previa al } \\
\text { descubrimiento de leyes. } \\
\text { 2) Rasgos que muestran la existencia de visiones acumulativas } \\
\text { lineales y rígidas: } \\
\text { - Se resalta que el conocimiento científico es el resultado de una } \\
\text { acumulación lineal y acrítica de conocimientos sin controversias, sin } \\
\text { saltos cualitativos ni retrocesos. } \\
\text { - Se acepta una visión normativizada del método científico que } \\
\text { consta de una serie rígida de etapas que hay que seguir. }\end{array}$ & $\begin{array}{l}\text { 3) Rasgos que caracterizan las concepciones hipotéticas y flexibles: } \\
\text { - Se resalta el papel esencial de las hipótesis en la construcción del } \\
\text { conocimiento científico. } \\
\text { - Se pone el énfasis en el planteamiento de problemas que surgen, } \\
\text { normalmente, del cuerpo teórico como punto de partida de la inves- } \\
\text { tigación. } \\
\text { - Se considera la realización de experimentos como fase importante, } \\
\text { aunque no única, para poner a prueba las hipótesis. } \\
\text { 4) Características de visiones acumulativas críticas y flexibles: } \\
\text { - Se pone el énfasis en el carácter controvertido del conocimiento } \\
\text { científico con frecuentes crisis que pueden llegar a constituir verda- } \\
\text { deras revoluciones científicas. } \\
\text { - Se acepta la existencia de estrategias generales y flexibles que } \\
\text { utiliza la ciencia para resolver problemas pero sin considerarlas } \\
\text { como recetas que hay que aplicar rígidamente. }\end{array}$ \\
\hline
\end{tabular}


Cuadro III

Rasgos característicos de las concepciones convencionales y constructivistas sobre el proceso de enseñanza-aprendizaje de las ciencias.

\begin{tabular}{|c|c|}
\hline $\begin{array}{l}\text { Rasgos de las concepciones convencionales sobre la enseñanza } \\
\text { y el aprendizaje de las ciencias }\end{array}$ & $\begin{array}{c}\text { Rasgos de las concepciones convencionales sobre la enseñanza } \\
\text { y el aprendizaje de las ciencias }\end{array}$ \\
\hline $\begin{array}{l}\text { 5) Se piensa, en esencia, que el proceso de enseñanza-aprendizaje ha } \\
\text { de reunir las siguientes condiciones: } \\
\text { - La enseñanza ha de transmitir de manera organizada los conoci- } \\
\text { mientos científicos aceptados como verdades. } \\
\text { - Lo que ya sabe el estudiante no es importante para la enseñanza } \\
\text { (hipótesis de la tabula rasa). } \\
\text { - El currículo ha de centrarse, fundamentalmente, en las teorías, } \\
\text { conceptos y principios de la ciencia que se va a enseñar. } \\
\text { - El aprendizaje requiere que los estudiantes tengan suficiente nivel } \\
\text { en su conocimiento anterior, que atiendan las explicaciones y que las } \\
\text { apliquen. } \\
\text { - Las relaciones entre enseñanza y aprendizaje son simples; es } \\
\text { decir, o bien se identifica enseñanza con aprendizaje (p.e., cuando } \\
\text { se enseña, siempre se aprende) o bien son totalmente indepen- } \\
\text { dientes (p.e., la falta de aprendizaje es debida al aprendiz y no a la } \\
\text { enseñanza). }\end{array}$ & $\begin{array}{l}\text { 6) Se piensa, en esencia, que el proceso de enseñanza-aprendizaje ha } \\
\text { de reunir las siguientes condiciones: } \\
\text { - La enseñanza ha de preparar de manera organizada las actividades } \\
\text { que faciliten la construcción hipotética de los conocimientos cientí- } \\
\text { ficos. } \\
\text { - La enseñanza ha de tener en cuenta lo que ya sabe y le interesa al } \\
\text { aprendiz. } \\
\text { - El currículo ha de centrarse en contenidos conceptuales, en formas } \\
\text { de razonamiento próximas a las científicas (contenidos procedimen- } \\
\text { tales) y en contenidos actitudinales (relaciones CTS). } \\
\text { - El aprendizaje requiere que los estudiantes se impliquen en el } \\
\text { tratamiento científico de situaciones problemáticas de interés ayuda- } \\
\text { dos convenientemente por el profesor. } \\
\text { - Las relaciones entre enseñanza y aprendizaje son complejas y no } \\
\text { deterministas. No obstante, se pone el énfasis en que la enseñanza es } \\
\text { uno de los principales factores que influyen en el aprendizaje. }\end{array}$ \\
\hline
\end{tabular}

cuestionario. El análisis de las ideas epistemológicas del profesorado, tanto en el pretest como en el postest, se realizaría sobre la base de los mismos criterios que se han explicitado en el documento 6 (Anexo).

\section{Indicadores utilizados para detectar el cambio en las concepciones docentes sobre el proceso de enseñan- za-aprendizaje de las ciencias}

Por lo que respecta a las ideas del profesorado sobre la enseñanza y el aprendizaje de la ciencias, uno de los primeros problemas es que, o no se establece ninguna relación entre enseñanza y aprendizaje, o se atribuye una relación simple de causa a efecto, de tal forma que, si la enseñanza del profesor/a (casi siempre concebida como la transmisión de conocimientos ya elaborados) es recibida por unos alumnos/as inteligentes, interesados y atentos, conduce necesariamente a aprendizaje. De ahí que los fracasos escolares se atribuyan a la propia ciencia (difícil de aprender) o al alumno (a su desmotivación o a su falta de capacidad). En todo caso, el profesor entiende que es necesario que el aprendiz aplique mediante realización de ejercicios el conocimiento transmitido que se supone ha sido aprendido. En esas supuestas aplicaciones, a veces, se incluye algún trabajo que requiere el aprendizaje de procedimientos en forma de instrucciones o algoritmos presentados directa o indirectamente por el profesor/a. Mucha menos importancia se concede a la formación de actitudes hacia la ciencia y su aprendizaje. Así pues, pocas veces se consideran en la enseñanza las ideas e intereses de los aprendices y, cuando se hace, se piensa en ellos como obstáculos, más que como punto de partida de nuevas construcciones.
En cualquier caso, teniendo en cuenta los principales paradigmas de enseñanza-aprendizaje (Gil, 1983), se pueden adscribir las concepciones de los profesores/as sobre el aprendizaje y la enseñanza a dos grandes categorías. Por una parte, será frecuente encontrar ideas próximas a modelos convencionales de enseñanza de las ciencias basados en la tansmisión verbal de conocimientos científicos ya elaborados cuyos principales rasgos se describen en el apartado 5 del cuadro III. Como categoría opuesta se ha pensado en modelos constructivistas de cambio conceptual, metodológico y actitudinal más acordes con los resultados de la investigación didáctica cuyas características se explicitan en el apartado 6 del mismo cuadro III.

De acuerdo con todo ello, el diseño elaborado ha de ser capaz de analizar las concepciones del profesorado sobre la enseñanza y el aprendizaje antes y después de intervenir en el programa base. Al igual que en las ideas sobre la ciencia, era de esperar que no todas las concepciones del apartado 5, por ejemplo, se presentarían conjuntamente, sino bastante independientemente. Puede haber profesores que consideran importante enseñar actitudes, pero que no concedan importancia a las ideas previas de los alumnos/as o que consideren que el fracaso en la enseñanza de las mismas se debe en exclusiva a la falta de dedicación de los alumnos, etc. Para ver las ideas del profesorado antes de participar en el programa se incluyeron las preguntas abiertas $2,3,4,5$ y 7 del cuestionario inicial (documento 1), las entrevistas correspondientes y otros instrumentos (transcripciones de los registros en audio de algunas sesiones de los equipos docentes en las que hubiera intervenido el profesor objeto de estudio, cuestionario cerrado con 30 ítems, 
etc.). Con el fin de tener información después de la participación de los profesores en los seminarios, se introdujeron en el cuestionario final (documento 2) las preguntas abiertas que van de la 5 hasta la 10, las entrevistas y otros instrumentos.

\section{Diseño para la observación de la práctica y del cam- bio de clima de aula}

En el diseño no sólo se ha previsto analizar el cambio en las concepciones del profesorado participante sino también ver si hay algún cambio en la forma de enseñar las ciencias en el aula. Para ello se seleccionaron aquellos aspectos formales de la práctica docente que pudieran ser observados directamente en el aula y que permitieran caracterizar el modelo de enseñanza implementado por cada profesor teniendo en cuenta lo indicado en el apartado anterior. Así en el modelo de transmisión, bastante frecuente, el profesor/a es el protagonista, ya que está en posesión de un conocimiento objetivo y verdadero que ha de transmitir. Los alumnos tienen poco o nada que aportar, ya que no lo conocen; por lo tanto, de poco sirve que participen o trabajen entre ellos (Porlan et al., 1997). Parece claro que, en clase, todo se debe organizar para que ese conocimiento se pueda transmitir y recibir en las mejores condiciones posibles. Así pues, al comienzo del programa de formación se espera que las características de la práctica de aquellos profesores que no conozcan la poca eficacia de la enseñanza convencional se aproximen a los rasgos contenidos en el apartado 7 del cuadro IV. En cambio, la parte 8 de este mismo cuadro representa el énfasis que se espera que pongan en la organización del trabajo y en el clima de aula aquellos profesores/as de ciencias que utilizan modelos de orien- tación constructivista. En el diseño no se ha previsto el análisis del tipo de actividades propuestas por el profesor desde el punto de vista de su contenido procedimental.

Con arreglo a lo anterior, se diseñaron instrumentos para analizar qué tipo de interacciones personales se favorecían en el aula. Se utilizó la observación no participante en las clases, actuando como observador externo el tutor y comentando los resultados de la observación con el profesor o profesora cuya clase se observaba. También se utilizó el registro en audio y vídeo de algunas clases. Para la observación directa en el aula se utilizó una plantilla diseñada al efecto por el tutor y presentada para su corrección y análisis al profesorado participante en los diferentes programas. En la parte izquierda de la plantilla se dibujaba la distribución habitual de los pupitres de los alumnos/as numerándolos. El observador utilizaba varias hojas con esta plantilla, una para cada actividad de las que se realizaban en clase. En cada hoja anotaba la actividad y hora de comienzo de la misma, así como las incidencias (movimientos del profesor, interacciones verbales, calidad de las mismas...). Para el análisis de los registros de la plantilla, de audio o de vídeo, se idearon y se aplicaron los criterios que se detallan en el documento 7 (criterios D' 1 a D'3 para la dirección de la actividad de los alumnos/as en clase; los O'1 a O' 5 para la organización espacial y temporal de las interacciones en clase y del C'1 a C' 4 para el clima de aula.

Se diseñó también un cuestionario para ser cumplimentado por los alumnos/as del grupo clase de cada profesor o profesora objeto de estudio, al que hemos denominado cuestionario de evaluación final del profesor/a por los

\begin{tabular}{|c|c|}
\hline $\begin{array}{l}\text { Énfasis puesto en la organización del trabajo en clase según el } \\
\text { modelo de transmisión verbal }\end{array}$ & $\begin{array}{c}\text { Énfasis puesto en la organización del trabajo en clase según el } \\
\text { modelo de aprendizaje por investigación }\end{array}$ \\
\hline $\begin{array}{l}\text { 7) La organización escolar más adecuada para conseguir un buen } \\
\text { clima de aula requiere las siguientes condiciones: } \\
\text { - La clase ha de organizarse para que los alumnos puedan recibir de } \\
\text { la mejor manera posible la información del profesor (pupitres en fila } \\
\text { frente a la mesa del profesor). } \\
\text { - El rol fundamental del profesor consiste en explicar bien la teoría } \\
\text { en las condiciones acústicas más adecuadas. } \\
\text { - El profesor procurará que los alumnos puedan escucharle atenta- } \\
\text { mente y, en todo caso, que apliquen la teoría expuesta mediante la } \\
\text { realización de ejercicios. } \\
\text { - El clima de aula idóneo será aquél que favorezca el silencio } \\
\text { cuando intervenga el profesor y cuando el alumno realice individual- } \\
\text { mente los ejercicios. Existirá poca interacción entre los propios } \\
\text { alumnos. }\end{array}$ & $\begin{array}{l}\text { 8) La organización escolar más adecuada para conseguir un buen } \\
\text { clima de aula requiere las siguientes condiciones: } \\
\text { - La clase se ha de organizar para que los alumnos trabajen } \\
\text { colectivamente en pequeños grupos que intentan resolver las activi- } \\
\text { dades propuestas (pupitres individuales agrupados de } 4 \text { en } 4 \text { y } \\
\text { orientados lateralmente hacia el profesor). } \\
\text { - El rol fundamental del profesor consiste en saber dirigir la activi- } \\
\text { dad grupal del alumnado mediante la implementación de programas } \\
\text { de actividades. } \\
\text { - El profesor procurará que los alumnos participen activamente en } \\
\text { los pequeños grupos y que haya interacciones grupales bien dirigidas } \\
\text { por él mismo. } \\
\text { - El clima de aula idóneo será aquél que favorezca la participación } \\
\text { y la interacción de los alumnos, la cooperación en el trabajo de aula } \\
\text { y el respeto a los demás. }\end{array}$ \\
\hline
\end{tabular}


alumnos/as (documento 5 ya citado). Ese mismo cuestionario era contestado por otros grupos-clase del mismo centro y nivel, de otros profesores/as que sirvieron voluntariamente de grupo control y cuyo formato, previamente se sabía que era próximo al expuesto en el apartado 7 del cuadro IV. En este cuestionario se consideraron los siguientes dimensiones: «los contenidos trabajados», «la forma de evaluar», «la forma de calificar», «la aptitud del profesor o la profesora» y «la satisfacción con que se ha trabajado en clase». En los resultados de estos cuestionarios se vería si hay diferencias significativas entre los grupos control y experimental en cada uno de los aspectos, pero, en particular, interesaba el campo «forma de trabajo en el aula».

\section{Indicadores del cambio actitudinal hacia la innova- ción e investigación didácticas}

El objetivo esencial perseguido en el programa de formación consistía en mejorar las actitudes de los profesores hacia los nuevos modelos de cambio conceptual y, en particular, en mejorar sus expectativas de desarrollo profesional. Ello supone que el profesor/a acabe motivado hacia su trabajo en el sentido de adquirir una actitud continua de mejora en su propio trabajo, que puede concretarse en ser conscientes de los aprendizajes realizados por ellos mismos y por sus alumnos y de estar dispuestos a iniciar innovaciones fundamentadas en la investigación didáctica. Este cambio actitudinal lo hemos operativizado en los indicadores que se indican en el cuadro $\mathrm{V}$.

Para constatar los cambios en los aspectos actitudinales, tres fueron los diseños que se idearon, dos de ellos eran introspectivos y el tercero, de valoración externa. El primero tenía por objeto facilitar que cada profesor
Cuadro V

Indicadores de actitudes positivas de los profesores hacia la innovación e investigación didácticas.

La hipótesis supone que los profesores/as que han participado en el programa de formación habrán mejorado sus expectativas profesionales y sus actitudes hacia la investigación. Ello se puede observar a través de los siguientes comportamientos:

- Serán conscientes del cambio experimentado en sus concepciones y práctica docente.

- Presentarán una actitud positiva hacia la investigación didáctica, valorando positivamente la innovación llevada a cabo.

- Participarán cooperativamente en la producción de innovaciones o investigaciones en didáctica de las ciencias (elaboración de materiales didácticos, presentación de comunicaciones en jornadas y congresos; publicación de artículos en revistas de investigación, etc.).

explicitara, según su percepción, los cambios experimentados en sus ideas y en su práctica educativa (preguntas 5, 6 y 10 del documento 2, preguntas 1 a y $1 \mathrm{~b}$ del documento 4 y la entrevista). Para facilitar la categorización de las respuestas se elaboró un conjunto de criterios (documento 8). El objetivo fundamental del segundo diseño consistía en que cada profesor expresara su grado de satisfacción después de haber puesto en práctica la innovación y sus expectativas respecto a su futura utilización en el aula (preguntas 2 y 3 del documento 4 y la entrevista). También en este caso se preparó un conjunto de categorías para el análisis de las respuestas (documento 9). En el tercer diseño se debía hacer el seguimiento externo durante un par de años sobre la producción didáctica de los grupos de profesores tutorados después de finalizar el programa de formación.

Cuadro VI

Resumen de los instrumentos utilizados.

\begin{tabular}{|l|l|}
\hline \multicolumn{1}{|c|}{ Diseños para constatar instrumentos } & Instrumentos \\
\hline $\begin{array}{l}\text { Cambios en la concepciones docentes } \\
\text { sobre la ciencia y la actividad científica }\end{array}$ & $\begin{array}{l}\text { Cuestionario inicial (documento 1) y final (documento 2) y entrevista sobre el } \\
\text { cuestionario final (documento 3), intervenciones en las sesiones. }\end{array}$ \\
\hline $\begin{array}{l}\text { Cambios en las concepciones sobre } \\
\text { de las ciencias }\end{array}$ & $\begin{array}{l}\text { Cuestionario inicial y final, entrevista sobre el cuestionario final, intervenciones } \\
\text { en las sesiones, cuestionario de concepciones. }\end{array}$ \\
\hline $\begin{array}{l}\text { Acción educativa de los profesores/as } \\
\text { Cambios en sus expectativas profesionales }\end{array}$ & $\begin{array}{l}\text { Plantilla de observación, registros en audio y vídeo, cuestionario de evaluación } \\
\text { final del profesor/a por el alumnado (documento 5). }\end{array}$ \\
\hline & $\begin{array}{l}\text { Cuestionario para valorar la estrategia metodológica (documento 4) y entrevista } \\
\text { complementaria sobre la estrategia metodológica, cuestionario final, entrevista } \\
\text { sobre el cuestionario final, cuestionario de expectativas (curso 1993-94). Docu- } \\
\text { mentos elaborados por los equipos y comunicaciones, artículos, etc. }\end{array}$ \\
\hline
\end{tabular}


Figura 1

Respuestas de Pepe sobre el diagrama de un ciclo de investigación antes y después del programa de formación
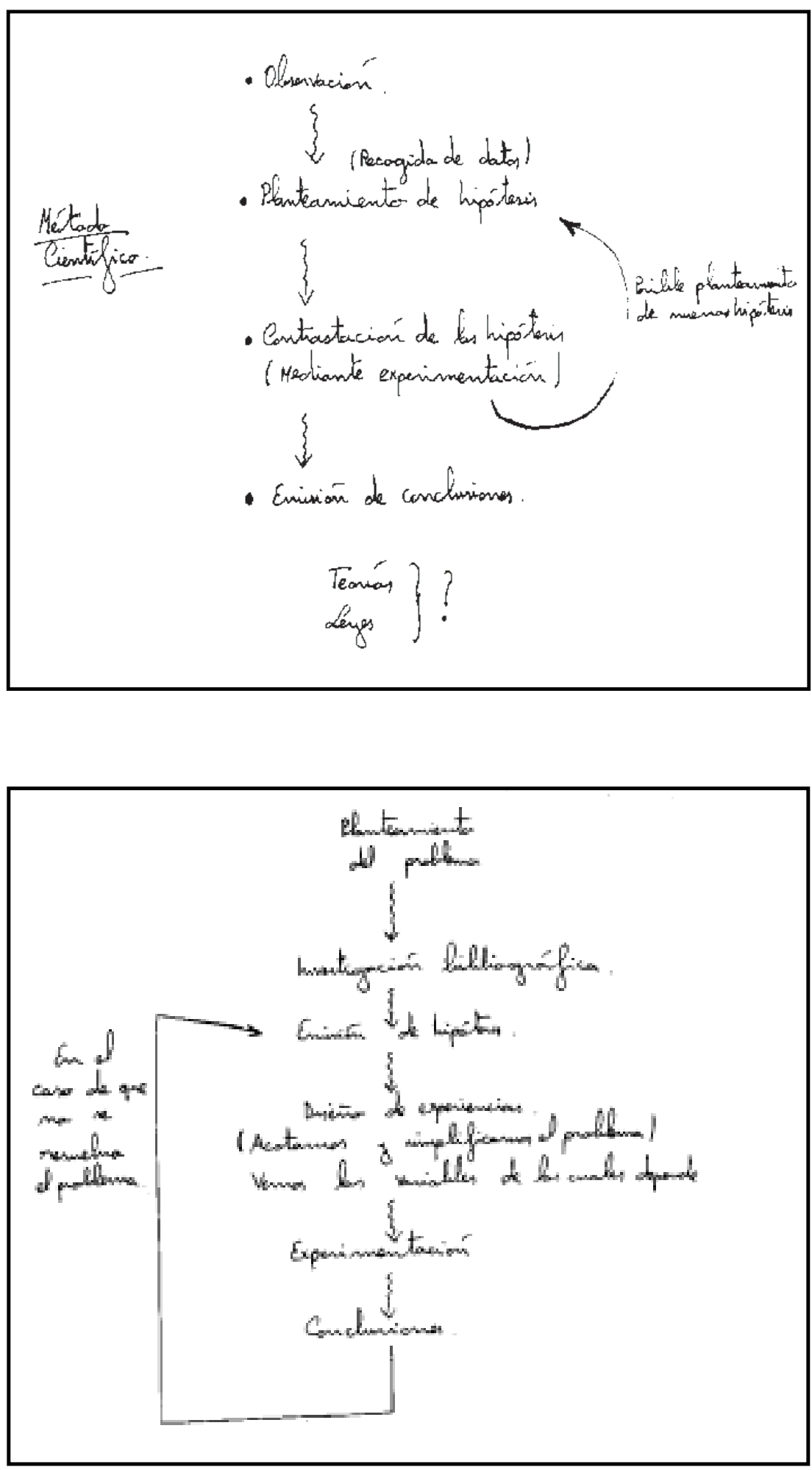
Figura 2

Diagramas expuestos por Ignacio antes y después del programa de formación.
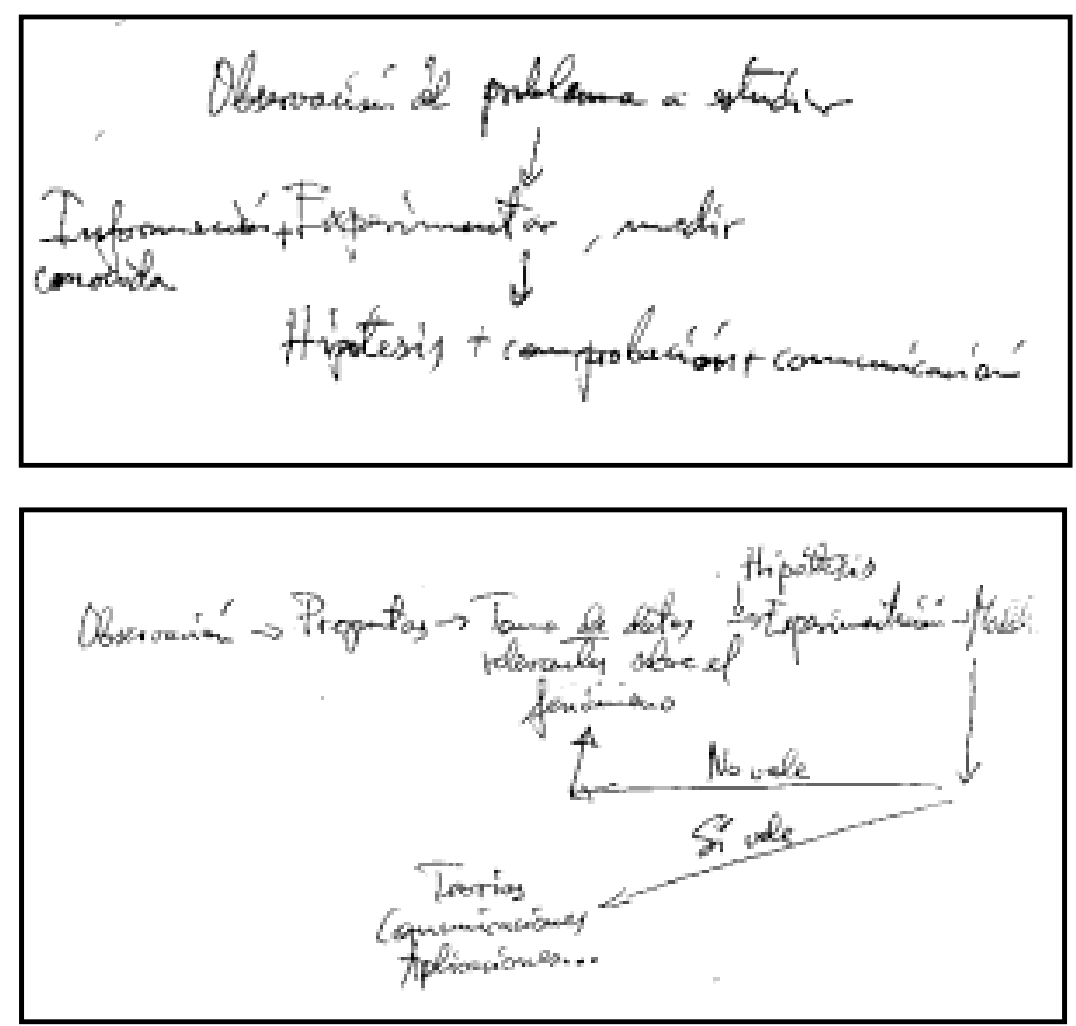

\section{Síntesis del diseño empleado en el análisis del cambio didáctico}

En el cuadro VI se han resumido los posibles cambios esperados en el profesorado después de participar en las tutorías y los instrumentos empleados para su contrastación.

\section{PRESENTACIÓN Y ANÁLISIS DE LOS RE- SULTADOS OBTENIDOS}

Al igual que se ha hecho en el apartado anterior, presentaremos y analizaremos por separado el cambio epistemológico, metodológico y actitudinal de los profesores que participaron en el programa. Ahora bien, con el fin de no extendernos demasiado, no se presentarán pormenorizados los cambios particulares de cada uno de los casos como suele ser habitual en este tipo de trabajos, sino que se presentarán agrupados aquellos profesores/ as cuyas concepciones y práctica docente iniciales o cuyos cambios, después de participar en el programa de formación, han sido parecidos.

\section{Concepciones epistemológicas iniciales sobre cómo se construyen los conocimientos científicos y cambios ocurridos después de participar en las tutorías}

Reme, al contestar a la pregunta 1 del cuestionario inicial, dibuja un diagrama de un ciclo de investigación en el que no aparecen rasgos relativos a posibles visiones empiristas e inductivistas de cómo se construyen los conocimientos científicos. En este dibujo se presentan las siguientes etapas: a) planteamiento del problema; $b$ ) emisión de hipótesis; c) comprobación de hipótesis (realización de experimentos); $d$ ) análisis de resultados (elaboración de conclusiones). No obstante, se interpretó que el esquema presentado era rígido y lineal debido a que no hay flechas que indiquen retroalimentación y a que presenta una secuencia simple sin ramificaciones. Esta interpretación se corrobora cuando, al preguntarle en la entrevista si podía haber variaciones en el orden de los procesos reseñados, contesta: No, yo creo que tienen que ir uno detrás de otro.

Algo semejante ocurría con Chusa, Jaime y Josefa, pues en sus diagramas estaban también alejados de posiciones empiristas. En cuanto a cómo concebían el proceso de 
construcción de los conocimientos científicos, lo consideraban un proceso complejo con saltos y regresiones a lo largo de la historia. Sin embargo, presentaban el método científico como una normativa rígida a seguir. Esta rigidez metodológica también se encontró en Pepe, Víctor e Ignacio, pero estos profesores, por el contrario, atribuían un origen sensorial al conocimiento científico. En sus ideas próximas a posiciones empiristas primaban la observación y la experimentación como el verdadero salto cualitativo que ha hecho progresar la ciencia. Así, por ejemplo, cuando se les pregunta cómo han ido evolucionando las ideas sobre los conocimientos que intentamos trabajar (pregunta 6 del cuestionario inicial), uno de ellos responde lo siguiente:

Primero han sido ideas filosóficas para explicar los diversos fenómenos sin comprobación, medida ni experimentación, a veces influidas por ideas religiosas, a veces esotéricas y mágicas, finalmente se ha contrastado con los procesos reales, medido y experimentado. (Ignacio).

Finalmente, Clara consideraba, antes de empezar el programa, la ciencia como una construcción humana y su idea sobre este proceso era bastante flexible y compleja, alejándose de concepciones empiristas y rígidas.

Después de participar en el programa, los cambios más grandes que se detectaron, fueron los de Pepe y Víctor.
Los dos abandonaron posiciones cercanas al empirismo en sus ideas sobre la naturaleza de la ciencia y el trabajo científico, acercándose a posiciones racionalistas que dan más importancia al cuerpo teórico de conocimientos de partida, al planteamiento de problemas en ese cuerpo y a la construcción de posibles soluciones a contrastar experimentalmente. Así, por ejemplo, Pepe ha dibujado dos diagramas de un ciclo de investigación bien diferentes antes y después de participar en el programa como puede verse en la figura 1 que se adjunta.

Reme y Chusa no podían cambiar mucho en este aspecto, puesto que ya partían de ideas cercanas a posiciones racionalistas. La visión rígida de los procedimientos mediante los que se construye la ciencia cambió en todos los profesores/as noveles menos en Chusa. Los demás, en mayor o menor medida, abandonaron visiones lineales y rígidas de la actividad científica.

Entre los experimentados, Clara apenas cambió sus concepciones porque ya tenía antes de participar en el programa ideas sobre la ciencia y su evolución próximas a las defendidas por la filosofía actual de la ciencia. Jaime podría haber cambiado sus concepciones rígidas sobre el método científico y la evolución de la ciencia, pero ése no fue el caso, quizás porque solamente participó en el Seminario 4. En cambio, Josefa abandonó posiciones lineales y rígidas sobre el método científico y cambió su visión acumulativa sobre la evolución de la

Cuadro VII

Respuestas a las preguntas 3 (documento 1) y 5 (documento 2) de Víctor, Clara e Ignacio.

\begin{tabular}{|c|c|c|}
\hline & ANTES & DESPUÉS \\
\hline Profesor & $\begin{array}{l}\text { Respuesta a la pregunta } 3 \text { : En general ¿cómo crees } \\
\text { que aprende en ciencias un alumno/a? }\end{array}$ & $\begin{array}{l}\text { Respuesta a la pregunta 5: En general, ¿cómo crees que aprende } \\
\text { ciencias un alumno/a? }\end{array}$ \\
\hline Víctor & $\begin{array}{l}\text { «Pienso que mal. Desde el primer momento se les } \\
\text { da un nivel alto, lo que les aburre, y rechazan el } \\
\text { estudio en su mayoría. Se dedican a utilizar los } \\
\text { conocimientos de forma mecánica.» }\end{array}$ & $\begin{array}{l}\text { «Pienso que primero habría que preguntarse qué es aprender } \\
\text { ciencias un alumno/a. ¿Qué es? ¿Aprender lo que les damos en } \\
\text { clase (en especial los contenidos)? ¿Aprender a pensar para abor- } \\
\text { dar cualquier cuestión, siendo lo más críticos y objetivos, sin } \\
\text { dejarse cegar por el sentido común o por otras creencias o ideas que } \\
\text { se tengan? ¿Despertar una serie de actitudes? ¿O quizás un com- } \\
\text { pendio de todo esto?» }\end{array}$ \\
\hline Clara & $\begin{array}{l}\text { «Fatal. Pretenden aprender de memoria, utilizar } \\
\text { fórmulas, no razonar causas. No saben presentar ni } \\
\text { analizar los problemas. No saben resolver un pro- } \\
\text { blema no planteado en clase.» }\end{array}$ & $\begin{array}{l}\text { «El alumno/a tiene que cambiar las ideas previas que tiene en } \\
\text { relación con un determinado contenido por otras que den respuesta } \\
\text { al problema planteado. Para ello plantea problemas de interés por } \\
\text { él y lo acata. Emite hipótesis según sus propias concepciones. } \\
\text { Elaborar estrategias por comprobar las hipótesis. Analiza los resul- } \\
\text { tados y los compara con las ideas de partida. Integra sus ideas en el } \\
\text { cuerpo de conocimientos general.» }\end{array}$ \\
\hline Ignacio & $\begin{array}{l}\text { «Conociendo y asimilando la teoría, realizando } \\
\text { ejercicios prácticos y problemas donde se utilizan } \\
\text { conceptos de forma clara, contrastando y aplicando } \\
\text { sus conocimientos teóricos y prácticos en expe- } \\
\text { riencias de laboratorio. El orden de estos pasos } \\
\text { puede variar según el tema, el tiempo y el tipo de } \\
\text { alumnos/as.» }\end{array}$ & $\begin{array}{l}\text { «Como todo lo demás: asimilando conceptos y teorías, aplicándo- } \\
\text { las y viendo, o creyendo, su utilidad. La nueva metodología } \\
\text { aplicada deja de ver que el proceso de aprendizaje puede ser más } \\
\text { trabajado, tratando de evitar así las falsas concepciones e ideas } \\
\text { previas, así mismo enseña cómo se construye la ciencia.» }\end{array}$ \\
\hline
\end{tabular}


ciencia. Pero el que menos cambió sus concepciones fue Ignacio, manteniendo las posiciones empiristas y rígidas con las que había partido. Véase a este respecto la semejanza entre los diagramas de un ciclo de investigación que dibujaba antes y después de programa de formación (Fig. 2).

En la tabla I que se presenta en los anexos se resumen los cambios epistemológicos producidos en los profesores/ as participantes en el programa.

\section{Cambios observados en el pensamiento del profeso- rado sobre aspectos importantes del proceso de ense- nanza-aprendizaje de las ciencias}

En lo relativo a las concepciones iniciales de los profesores sobre el proceso de enseñanza-aprendizaje de las ciencias, también se observó cierta diversidad en los modelos didácticos asumidos por los profesores noveles y experimentados, como era de esperar. Chusa, Reme, Pepe, Josefa y Jaime partían de posiciones cercanas a modelos de aprendizaje basados en la construcción social del conocimiento, si bien cada uno tenía matices particulares. Así, por ejemplo, veamos la transcripción literal de la breve contestación dada por Chusa a la pregunta 3 del documento 1 sobre cómo aprenden los alumnos:

\section{"Aprende cuando es capaz de entender e interpretar por} sí mismo.»(Chusa)

Además, al preguntarle en la entrevista sobre esta cuestión, comenta la poca eficacia de la enseñanza por transmisión en la que el papel principal del profesor es explicar los conceptos una y otra vez. Coherentemente, Chusa sigue opinando que han de ser los propios alumnos los que han de descubrirlos, trabajándolos. Del contenido de estas respuestas se puede interpretar que sus ideas se aproximan a un modelo de aprendizaje por descubrimiento autónomo (Gil, 1983). Este pensamiento intuitivo es bastante frecuente en aquel profesorado que está insatisfecho con el modelo de transmisión verbal y que ha asumido como problema el poco aprendizaje significativo logrado por sus alumnos.

En cambio, dos profesores experimentados (Clara e Ignacio) y uno novel (Víctor) partían de concepciones próximas al modelo de transmisión de los conocimientos ya construidos, como puede observarse en las respuestas a la pregunta 3 de estos tres profesores que se presentan en la primera columna del cuadro VII.

Al finalizar el programa de formación, todos los profesores/as noveles o experimentados cambiaron en mayor o menor medida sus concepciones iniciales, si exceptuamos, también aquí, el caso de Ignacio. A esta conclusión se puede llegar al interpretar y comparar, por ejemplo, las respuestas de Víctor, Clara e Ignacio a la pregunta 5 del cuestionario final (segunda columna del cuadro VII). Como vemos, Ignacio sigue enfatizando un modelo de aprendizaje en el que el estudiante ha de asimilar la teoría, explicada previamente por el profesor, y aplicarla mediante la realización de ejercicios y problemas. No ha ocurrido lo mismo con Víctor y Clara, que han asumido que el aprendizaje es un proceso complejo en que el alumno ha de llegar a mostrar cierto conocimiento procedimental y explicativo además del declarativo. En resumen, al final del programa, siete de los ocho profesores/as participantes tenían concepciones que se acercaban a posiciones que consideran el aprendizaje y la enseñanza como una construcción social del conocimiento y uno sólo, Ignacio, seguía pensando en la transmisión-recepción del conocimiento científico como mejor modelo de enseñanza-aprendizaje. Pero no por ello todas estas posiciones ante el proceso de enseñanzaaprendizaje deben considerarse idénticas. Veamos varios ejemplos de esta diversidad al concretar algunos de sus pensamientos sobre los indicadores expresados en el cuadro III, tales como las ideas de los alumnos, la enseñanza, los contenidos del currículo y las relaciones entre enseñanza y aprendizaje.

Cinco de los ocho profesores/as (Pepe, Reme, Chusa, Jaime y Josefa), antes de participar en el programa de formación, se referían a las ideas previas, con este nombre o con otros (preconceptos, errores conceptuales, etc.). Pero, de estos cinco, solamente Pepe los consideraba como punto de partida de nuevos aprendizajes. Reme, Chusa, Jaime y Josefa se referían a las preconcepciones como obstáculos para aprender y que, por lo tanto, hay que «desechar». Los otros tres profesores (Clara, Ignacio y Víctor) apenas las consideraban. Ignacio incluso los confunde con los prerrequisitos, como puede verse en sus aclaraciones en la entrevista a la pregunta 5 del cuestionario inicial (documento 1).

Pregunta 5: Para diseñar una unidad didáctica, ¿qué debemos tener en cuenta? ¿Sobre qué deben tratar las primeras actividades que propongamos a nuestros alumnos?

Jesús: «Contestas que hay que tener en cuenta las ideas previas, ¿a qué te refieres con ideas previas?»

Ignacio: "Me refiero a sus conocimientos anteriores, a lo que un alumno/a debe saber para poder seguir lo que vamos a explicarle, por ejemplo si queremos explicar la $2^{a}$ ley de Newton. Antes tendrán que saber lo que es masa y lo que es aceleración.»

Sin embargo, después de participar en el programa, todos los profesores/as se refieren a las ideas previas y además todos, a excepción de Ignacio, las consideran como el punto de partida de nuevos aprendizajes. Clara lo expresa así en su respuesta a la pregunta 5 que se recoge en el cuadro VII. También Víctor lo expresaba claramente respondiendo a la pregunta 9 del cuestionario final.

Pregunta 9. Imagina que quieres introducir el concepto de fuerza (en particular, el segundo principio de Newton), describe brevemente las fases o etapas de la estrategia metodológica que utilizarías.

«En primer lugar, dejaría que ellos expusieran sus ideas previas acerca del tema y que quedaran registradas por escrito. Después haría una introducción del tema, histórica, relacionándola con las ideas previas que tienen, y 
plantearía la pregunta a responder en esta actividad, por ejemplo, los efectos de las fuerzas. A partir de aquí, con diferentes actividades, se trataría de poner en claro los conceptos de fuerza, principios que se quieren enseñar, por contraposición con las ideas previas, mediante la discusión y experimentación si hace falta. Por último, creo que se debería hacer un resumen de las conclusiones y contrastarlas con las ideas que se tenían al principio.» (Víctor)

Algo semejante ocurre con las concepciones que se tienen de la enseñanza. Tres profesores/as (Víctor, Clara y Ignacio) consideraban antes de participar en el programa (coherentemente con su idea de lo que es aprender, indicado antes) que enseñar consistía fundamentalmente en transmitir conocimientos por parte del profesor/a. El alumno/a debe asimilar este conocimiento y aplicarlo reiteradamente para aprenderlo. Ignacio lo expresaba claramente en su respuesta a la pregunta 3 que se recoge en el cuadro VII. Reme, Chusa, Pepe, Jaime y Josefa, después del programa, consideraban la actividad del profesor/a como algo más que una transmisión, acercándose a posiciones que lo consideran como facilitador de los aprendizajes de los alumnos/as. Sirva de ejemplo la respuesta de Clara a la pregunta 8 del cuestionario final.

Pregunta 8. Haz una valoración global de tu experiencia respecto a esta manera de enseñar las ciencias (características que te han llamado la atención respecto a: formas de presentación de las tareas al realizar la clase, funciones principales del profesor, papeles principales de los alumnos/as, relaciones en la clase, cambios en la enseñanza habitual...).
«Formas de presentación de las tareas al realizar la clase: Presentar las tareas en forma de actividades me parece muy bien aunque algunas son modificables pues pueden resultar poco concretas o demasiado largas y los alumnos/as no son capaces de fijar su atención y trabajo durante mucho tiempo. Hay que desmenuzar algunas actividades. La puesta en situación, muy importante para recapitular lo trabajado hasta el momento y para centrar el trabajo posterior.

Funciones principales del profesor/a: Me parecen muy bien sus funciones, aunque yo personalmente debo evitar dirigir demasiado a los alumnos/as, disminuir mi participación e incitar a que ellos lo hagan más. Papeles principales de los alumnos/as: Sobre todo les cuesta, al principio, concentrarse en el trabajo en el pequeño grupo y aportar, todos, sus ideas. Y en la puesta en común es muy difícil la participación de todos los alumnos/as. Siempre hay alumnos/as que participan mucho y otros que no lo hacen nunca. Relaciones en clase: Mejoran mucho a lo largo del curso y, si todos asumimos nuestras funciones y trabajo, el resultado es muy bueno. Cambios en la enseñanza habitual: El trabajo en el aula es mucho mejor. El profesor/a se siente mucho más contento en el trabajo diario. Los alumnos/as no son meros espectadores, sino que participan y ellos mismos llevan a cabo la clase.» (Clara)

Otro de los aspectos estudiados ha sido ver la importancia que tenía para el profesorado los diferentes tipos de contenidos (conceptuales, procedimentales y actitudinales) del currículo. Después de participar en el programa, todos los profesores/as, a excepción de Ignacio,

Cuadro VIII

Distribución temporal en las clases de Ignacio antes de participar en el programa de formación.

\begin{tabular}{|l|c|c|c|c|c|c|c|}
\hline Grupo-clase & Fecha & $\mathbf{t}_{\text {presentación }}$ & $\mathbf{T}_{\text {resol-ejerc. }}$ & $\mathbf{t}_{\text {expos-ejerc-piz. }}$ & $\mathbf{t}_{\text {coment-ejerc. }}$ & $\mathbf{t}_{\text {expl-prof }}$ & $\mathbf{t}_{\text {real clase }}$ \\
\hline $2^{\text {o de BUP }}$ & $25-5-92$ & 2 & 0 & 0 & 15 & 25 & 42 \\
\hline $2^{\text {o de BUP }}$ & $26-3-92$ & 8 & 26 & 16 & 0 & 0 & 48 \\
\hline
\end{tabular}

Cuadro IX

Distribución de tiempos de intervención en dos clases de Reme.

\begin{tabular}{|l|c|c|c|c|c|c|c|}
\hline Grupo-clase & Fecha & $\mathbf{t}_{\text {presentación }}$ & $\mathbf{t}_{\text {pequ-grupo }}$ & $\mathbf{t}_{\text {puesta común }}$ & $\mathbf{t}_{\text {debate }}$ & $\mathbf{t}_{\text {expl-prof }}$ & $\mathbf{t}_{\text {real clase }}$ \\
\hline $3^{\text {o de ESO }}$ & $5-3-93$ & 7 & $7+8$ & 6 & 15 & 2 & 45 \\
\hline $3^{\text {o de ESO }}$ & $8-3-93$ & 5 & 20 & 5 & 10 & 0 & 40 \\
\hline
\end{tabular}


consideraban relevantes tanto los contenidos conceptuales como los procedimentales y actitudinales. Sin embargo, antes de participar en el programa, tres de los ocho profesores/as participantes (Chusa Ignacio y Jaime) reducían éstos a los conceptuales. Reme, Pepe y Josefa consideraban además los procedimentales como importantes, mientras que, para Víctor, eran importantes los conceptuales y los actitudinales. Solamente Clara consideraba relevantes los tres tipos de contenidos como se interpreta al analizar lo que manifiesta en su respuesta a la pregunta 2 del cuestionario inicial que se presenta a continuación.

Pregunta 2.¿Para qué crees que sirve enseñar ciencias en estos niveles?

- Comprender los fenómenos que cada día el alumno/a puede ver a su alrededor.

- Intentar explicar las causas o el porqué de distintos fenómenos de la naturaleza.

- Relacionar la química con el ámbito de las aplicaciones tecnológicas.

- Interesar al alumno/a por el mundo que le rodea.

- Redescubrir las leyes que rigen el comportamiento del Universo.

- Qué el alumno/a sea capaz de interpretar, comprender y juzgar lo que ocurre a su alrededor y desenvolverse ante nuevas situaciones.

Finalmente y en cuanto a las relaciones entre dificultades de aprendizaje y enseñanza, la mayoría de los profesores experimentados (Ignacio, Clara y Josefa) señalaban, antes de participar en el programa de formación, que las dificultades del aprendizaje de sus alumnos eran debidas exclusivamente a los alumnos. Por ejemplo, en la cuestión 4 del cuestionario inicial relativa a cuáles creían que eran sus principales dificultades, Ignacio contesta:
«Dificultad en las operaciones de pensamiento abstracto. Resolución de problemas (no ejercicios). Diferentes ritmos de trabajo (del alumno) en clase y casa.» (Ignacio)

Como puede observarse, este profesor considera que la falta de capacidad intelectual de los alumnos, la dificultad intrínseca de la tarea (resolver problemas) o su poco interés en el trabajo son los factores relevantes en el noaprender. No hay en su respuesta referencia alguna de la posible influencia de una enseñanza inadecuada. En cambio, las respuestas a esta misma cuestión de todos los profesores noveles hacían, al menos, alguna mención indirecta a estas relaciones al considerar como dificultad de aprendizaje, por ejemplo, la falta de adaptación del alumno a nuevas formas de enseñanza más activas. Aquí sí que parece que hay diferencias según los años de experiencia del profesor/a.

Después de participar en el programa, casi todos los profesores habían mejorado en su percepción de la complejidad del proceso de enseñanza-aprendizaje a excepción de Ignacio. Por ejemplo, ante la pregunta $7 \mathrm{del}$ cuestionario final relativa a las dificultades de aprendizaje en la unidad didáctica que se había trabajado, este profesor da una respuesta como la que sigue:

«La idea de vacío. Establecimieto de las leyes de los gases a través de razonamientos cinético-particulares (quiere decir, corpusculares). Concepto de mol. Causas: la propia dificultad del concepto, las ideas y conocimientos previos...» (Ignacio)

En esta respuesta manifiesta cierto conocimiento de la literatura didáctica, ya que enumera tres problemas que se han trabajado dentro de la línea de investigación de las concepciones alternativas. No obstante, este conocimiento didáctico le sirve para fundamentar el pensa-

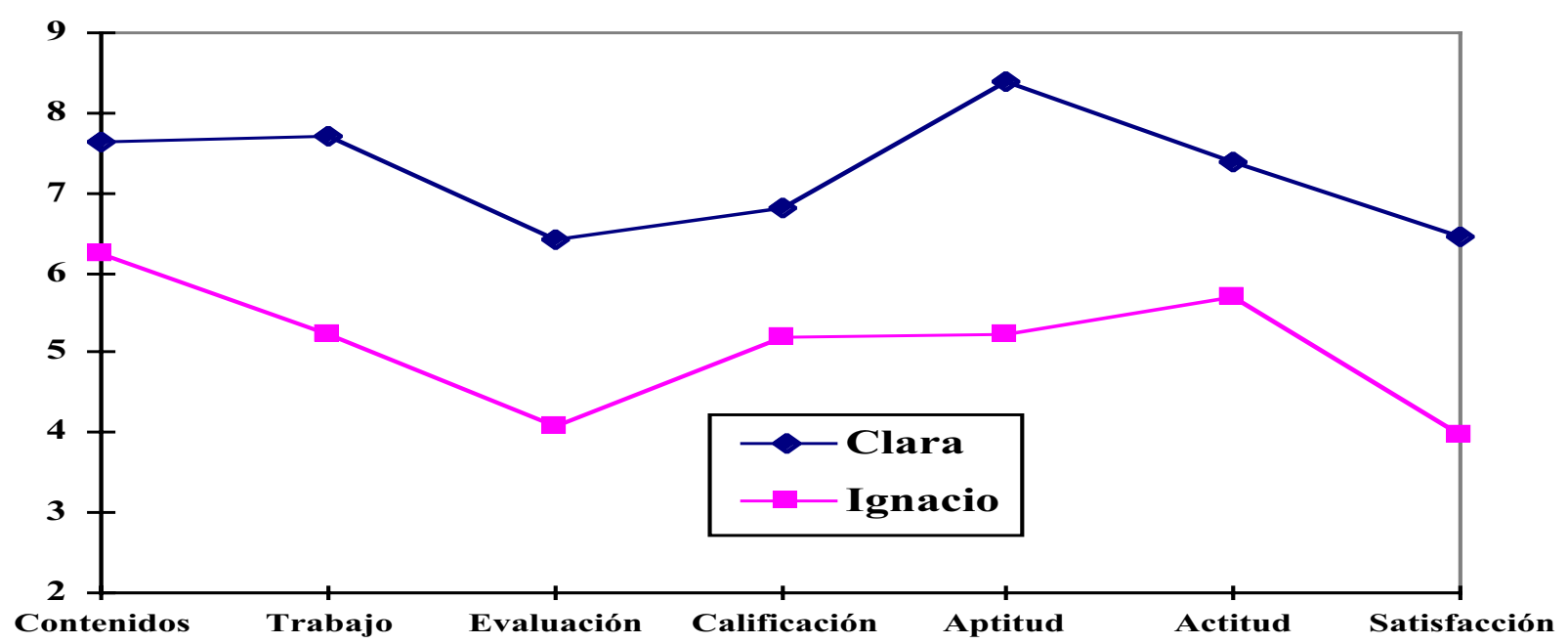


miento docente que ya tenía antes de empezar el programa sobre las causas del fracaso escolar: la dificultad de las propias disciplinas científicas, las derivadas de la falta de base (ideas y conocimientos previos) o las ganas de aprender del propio alumno. A estas conclusiones se ha llegado analizando también sus respuestas en la entrevista y en otras preguntas del mismo cuestionario final y del realizado al valorar las nuevas estrategias metodológicas, que no transcribimos por razones de espacio.

A la vista de los resultados encontrados y que se han resumido en la tabla II del anexo, podemos considerar confirmada nuestra hipótesis en el sentido de que, en general, la participación de los profesores de los diferentes equipos constituidos en el desarrollo del programa produjo cambios en la «epistemología personal docente» si exceptuamos a Ignacio, en el que no se detectaron cambios en sus concepciones a pesar de que llegó a poner en práctica la innovación propuesta durante tres meses. Pasemos ahora a analizar los cambios en la práctica educativa y las expectativas profesionales que generó el programa de formación.

\section{Cambios observados en la práctica de aula}

Con respecto a la práctica educativa, antes de participar en el programa sólo se pudieron observar las clases de Clara, Ignacio y Víctor, y en los tres casos podemos afirmar que estructuraban sus clases de ciencias de tal forma que el principal protagonista era el profesor o la profesora. En cambio, Víctor y Clara (ésta última en la segunda clase observada) introducían elementos que daban más protagonismo a los alumnos/as. Hay que señalar que la segunda clase de Clara fue observada cuando llevaba ya dos cursos participando en el programa de formación, aunque todavía no se habían experimentado en el aula las estrategias metodológicas que se proponían en dicho programa. En cambio, Víctor estaba intentando ponerlas en práctica, desde un principio, con ayuda de un compañero y después de haberlas leído en un libro. Sirvan de ejemplos prototípicos de clase convencional la distribución de los tiempos de intervención del profesor y de los alumnos en las dos clases de Ignacio que se observaron (Cuadro VIII). En la primera de las clases llama la atención el elevado tiempo de explicación del profesor (25 minutos sobre 42 que duró) mientras en la segunda, el profesor ha centrado la clase en la resolución de ejercicios y problemas (26 minutos sobre 48) aplicando la teoría impartida anteriormente.

En cuanto a estas prácticas de aula se resalta que, con mayor o menor profundidad, todos (incluso Ignacio en los tres meses que experimentó las nuevas estrategias) consiguieron dirigir sin problemas la clase de forma que aumentara el protagonismo de los alumnos/as. La mayor parte del tiempo organizaron la clase en pequeños grupos de trabajo que ponían en común las conclusiones de sus trabajos y, ayudados por las reformulaciones del profesor/a, se intentaba favorecer la construcción de los conocimientos logrando crear un clima participativo y de cooperación. Al menos así fue corroborado por la observación sistemática de las clases y por el alumnado de estos profesores/as en las clases en que pudo realizarse ese análisis. El cuadro IX muestra la distribución espaciotemporal de dos clases de Reme. En los registros realizados puede observarse el peso de la intervención de los alumnos bien en los pequeños grupos o bien interaccionando con el resto de los grupos y con el profesor.

Estas nuevas formas de dar la clase es lógico que, dado el mayor protagonismo del alumnado, fuesen bien aceptadas por los estudiantes. Esta suposición se puso a prueba al aplicar el cuestionario de evaluación final del profesor/a por los alumnos/as (documento 5) y analizar los resultados obtenidos en la valoración que los propios alumnos hacen de su clima de aula. Sirva de ejemplo la figura 3 en la que se representan los resultados de dicho cuestionario para la clase de Ignacio, al que sirvió de grupo control la clase de su compañera Clara. Hay que señalar que Ignacio había participado en el programa de formación los dos cursos anteriores y durante el último se había retirado voluntariamente volviendo a impartir las clases como lo hacía antes de participar en el programa. Los alumnos valoran en todos los casos mucho más positivamente la forma de trabajo en el aula cuando sus profesores/as ponen en práctica las nuevas estrategias metodológicas de enseñanza y aprendizaje por investigación, tal y como se propugnaba en el programa de formación que estaban desarrollando. Conviene resaltar que hubo casos, como el de los alumnos de Jaime, en que se valoró menos su actitud hacia el aprendizaje que la de su colega con el que se le comparó y, sin embargo, la forma de trabajo en la clase de Jaime fue mucho más valorada $(7,5)$ que la de su compañero $(5,5)$.

En resumen, estos resultados contribuyen a confirmar que el programa de formación que se desarrolló favoreció la adquisición de las destrezas necesarias para el cambio esperado en la práctica del profesorado objeto de estudio. Pero la simple práctica de estas nuevas formas de enseñanza por el profesor en el programa de formación no implica que realmente haya habido un cambio didáctico. Es necesario que el profesor asuma estas nuevas destrezas como parte del nuevo modelo didáctico (cambio conceptual y epistemológico) y que las valore positivamente hasta el punto de que no sólo advierta que sus alumnos están más satisfechos en el aula sino que, además, esté convencido de que su implementación mejorará el aprendizaje de sus alumnos (cambio actitudinal positivo hacia la innovación propuesta).

\section{Cambios actitudinales y expectativas de desarrollo profesional}

En cuanto a sus actitudes y expectativas hacia la innovación propuesta, todos los profesores/as participantes, a excepción de Ignacio, las han mejorado, valorándola positivamente y piensan seguir practicándola en sus clases. Estos siete profesores señalan su gran interés por mejorar su pericia en la dirección y organización de la clase. Algunos como Víctor, no solamente valoran positivamente estas nuevas estrategias, sino que van más allá y se plantean nuevas cuestiones. Veamos su respuesta a 
la pregunta 4 del cuestionario de expectativas (documento 9):

Pregunta 4. Señala las razones por las que continúas o inicias el trabajo en clase con esta estrategia metodológica.

«Me parece una buena estrategia metodológica, y, como pienso seguir con ella, se trata de prepararme para trabajar con ella. Pero me gustaría conocer otras estrategias, y otras formas de trabajo, y ampliar los conocimientos teóricos en los que se basa esta metodología.» (Víctor)

Puede observarse cómo este profesor se plantea conocer más en profundidad el fundamento teórico de esta innovación e, incluso, conocer otras formas de trabajo que puedan mejorar sus conocimientos didácticos.

No obstante, a pesar de este cambio de actitud de siete de los ocho profesores/as que participaron en el programa, todavía en algunos casos se hacían referencias a las tres grandes dificultades que se han señalado en la literatura para el cambio didáctico, como son: el reduccionismo conceptual en el currículo, no tener en cuenta que el aprendizaje requiere profundidad en el tratamiento de los conceptos y teorías y el aislamiento profesional del profesor/a. Pepe señalaba las dos primeras dificultades en su respuesta a la pregunta 2 del mismo cuestionario anterior (documento 9).

Pregunta 2. Valora la estrategia metodológica que estamos poniendo en práctica respecto del trabajo de los alumnos y de su aprendizaje. Señala algunas ventajas e inconvenientes de la misma en este aspecto.

«Creo que los alumnos/as trabajan más (actividad mental) y aprenden mejor. El principal problema que veo es el tiempo, si bien lo que aprenden, lo aprenden mejor, en ocasiones es un método muy lento que te hace sacrificar muchos contenidos conceptuales. La principal ventaja es que los alumnos/as participan activamente en el proceso y trabajan prácticamente por igual los tres tipos de contenidos.» (Pepe)

Y Josefa, en su respuesta a la pregunta 3 del mismo cuestionario, indicaba la importancia del tercer tipo de problemas al referirse a la importancia de que el profesor disponga de apoyos externos, en este caso del asesor (último párrafo), y volvía a referirse al segundo (líneas 10 a 13 inclusive), al indicar la falta de tiempo para abordar todos los contenidos del currículo.

Pregunta 3. Valora la estrategia metodológica que estamos poniendo en práctica respecto al trabajo del profesor y su enseñanza. Señala algunas ventajas e inconvenientes de la misma en este aspecto.

«Ventajas: Se detectan mejor las ideas previas de los alumnos.

»Se valora más objetivamente el aprendizaje de los alumnos, no se da la prioridad a quien es merecedor de una buena o mala nota, sino a quien necesita más o menos ayuda para alcanzar los objetivos propuestos al principio.

» ¿Quizás por ello los alumnos no están tan pendientes de alcanzar una nota como de conseguir unos mejores aprendizajes?

»Inconvenientes: Dificultad en el diseño de actividades al tener que conseguir que el alumno no recurra a su memoria para responderlas y tener todas un hilo conductor, ya que del buen diseño de las actividades depende en gran medida el éxito de este tipo de metodología.

»Al ir más lento que en la metodología tradicional, a veces no se pueden cubrir los programas.

»El profesor ha de dedicar mucho más tiempo de clase para planificar las actividades, objetivos, corregir cuadernos, etc.

»"En general" los profesores no están preparados para llevar a cabo este tipo de metodología, pienso. Se debería empezar por una preparación más profunda del profesorado antes de llegar al aula y no teniendo que aprender sobre la marcha, esto en el mejor de los casos, teniendo asesores más o menos competentes, pues en caso contrario ni siquiera el profesor se atreve a plantearse esta metodología.» (Josefa)

En cambio, muy diferente es la escueta respuesta de Ignacio a esta misma pregunta 3 :

«Ventajas: Si los alumnos colaboran, más satisfacción por la labor realizada en el aprendizaje lógico por parte de los alumnos. Inconvenientes: Más lento (Programas - de actividades-extensos). Más trabajo (se supone que quiere decir "para el profesor").»(Ignacio)

En la entrevista, este profesor señala que no tiene intención de continuar practicando las estrategias didácticas que se han puesto en práctica y, aunque pone condiciones de cambios estructurales (menor número de alumnos, de grupos por profesor y de contenidos), el problema, en el fondo, más bien es de tipo actitudinal. Basándonos en la transcripción de la entrevista, se interpreta que las actitudes de Ignacio hacia las nuevas estrategias no son positivas. El modelo «normal» de enseñanza para él está explícito cuando dice:

«Hombre, tal vez llegue un día, dentro de unos años, en que lo normal fuesen las clases por actividades, constructiva... y discutiendo y lo anormal fuese lo otro, pero por ahora lo anormal es esto (enseñanza por grupos cooperativos) y es más trabajoso, más costoso.» (Ignacio)

La creencia normativa de Ignacio sobre el mejor método de enseñanza, aunque parece mantener una postura ecléctica, es la que le decide a continuar transmitiendo los conocimientos y no a desarrollar programas de actividades. Tiene una predisposición negativa hacia las nuevas estrategias que justifica en base a que no se dan las 
condiciones externas favorables a su implementación (elevado número de alumnos y muchos contenidos).

Por otra parte, la participación durante el desarrollo del programa y con posterioridad de los profesores/as participantes en grupos de innovación e investigación corrobora el cambio actitudinal experimentado por los siete profesores/as restantes. Por ejemplo, Víctor elaboró junto con su compañero de seminario una comunicación presentada a las VI Jornadas de Experiencias Docentes. Todos los componentes del Seminario de Ciencias de la Naturaleza elaboraron otra comunicación presentada en el IV Congreso Internacional de Enseñanza de las Ciencias celebrado en Barcelona en septiembre de 1993 (Carnicer et al., 1993). También estos mismos profesores/as elaboraron la comunicación «El registro de clases en vídeo y su utilización en la investigación educativa», que se presentó en las VII Jornadas de Experiencias Docentes en Educación Infantil, Primaria y Secundaria celebradas en Alcañiz (Teruel) en septiembre de 1994 (Carnicer et al., 1994). Después de finalizado el programa de formación, Reme, Jaime, Pepe, Josefa, Clara y Jesús (tutor) siguieron como grupo y realizaron un trabajo sobre la evaluación de la enseñanza en clase de ciencias, trabajo que se presentó como ponencia en el curso: «Aspectos didácticos de Física y Química (Química)», organizado por el ICE de la Universidad de Zaragoza y celebrado en esta ciudad en septiembre de 1996 (Carnicer et al., 1997).

\section{CONCLUSIONES}

En general, podemos decir que se ha puesto a prueba la hipótesis principal de este trabajo, y los primeros resultados obtenidos en la mayoría de los casos presentados parece que la confirman. La hipótesis propugnaba que el desarrollo de un programa de formación fundamentado en el trabajo cooperativo tutorado lograría un cambio didáctico en los profesores participantes, independientemente de su experiencia profesional. Este cambio didáctico es complejo, ya que supone tener en cuenta los siguientes aspectos: un cambio epistemológico respecto a la ciencia y su enseñanza, un cambio metodológico en su comportamiento docente y un cambio actitudinal hacia la investigación didáctica y en las expectativas de desarrollo profesional. El cambio didáctico ha sido posible en siete de los ocho profesores gracias a que tenían unas expectativas profesionales que se han visto satisfechas gracias a un programa en el que se han planteado y resuelto problemas didácticos de interés para los participantes mediante la reflexión colectiva en pequeños grupos. Así, por ejemplo, tres profesores/as noveles (Reme, Pepe y Víctor) habían intentado, antes de participar en el programa, poner en práctica esta clase de estrategias metodológicas sin conseguirlo adecuadamente. Chusa, la cuarta profesora novel, Clara y Jaime fueron los que experimentaron un cambio más radical, pues sus clases, antes de participar en el programa, se estructuraban de forma que: a) el principal protagonista era el profesor/a; b) la clase se organizaba en filas para que los alumnos/as pudieran recibir el mensaje del profesor/a; $c$ ) no se concedía importancia a conseguir un clima de aula participativo y cooperativo. Se puede afirmar que adquirieron estas habilidades después de participar en el programa.

El caso de Ignacio es auténticamente sorprendente, ya que fue capaz de trabajar con arreglo a la estrategia metodológica propuesta en el programa durante el trimestre que duró la experimentación, para volver, en cuanto terminó ésta, a su forma de dar la clase tradicional. Parece que aprendió el procedimiento, pero no le convenció el modelo de enseñanza subyacente. Para Ignacio, que partía de actitudes distantes hacia estas formas de trabajar en el aula y de unas concepciones hacia la ciencia y su enseñanza bien trabadas, el programa ni satisfizo sus expectativas (que la tarea de enseñanza sea más efectiva, agradable y fácil) ni le aportó suficientes valores para que cambiara su epistemología docente y su práctica.

Otra característica importante del programa es que el apoyo dado en las tutorías requiere un seguimiento prolongado en el tiempo (un promedio de dos cursos académicos). Se ha de tener en cuenta que las concepciones y práctica docentes son difíciles de cambiar, no obstante, el programa ha permitido cambiar la práctica de todos los profesores noveles participantes y de parte de los experimentados. El cambio persistió después de concluir el programa y, lo que es mejor, ha favorecido la inmersión de los profesores que quisieron en la investigación didáctica.

En resumen, el cambio didáctico del profesorado ha de concebirse como continuo y «natural» en el «aprender a enseñar ciencia», y esencial para su desarrollo profesional. Ello implica que hay que preparar al profesor no sólo para enseñar ciencia sino también para trabajar colectivamente y autoevaluar su tarea. Y ello sólo será posible si se planifica la enseñanza como una hipótesis didáctica que trata de resolver el fracaso escolar y se pone a prueba mediante los oportunos diseños como en cualquier investigación (Furió, 1994). En este sentido es necesario implementar programas eficaces para conseguir la formación de grupos de profesores innovadores o de futuros investigadores. En este trabajo se presenta un modelo de formación de profesores cuyos primeros resultados parecen prometedores. Es cierto que, como indica Bell (1998), estos cambios son lentos pero es lógico, puesto que ya sabemos que, incluso para el profesor, aprender no es fácil. 


\section{REFERENCIAS BIBLIOGRÁFICAS}

BELL, B. (1998). Teacher development in Science Education, en Fraser, B.J. y Tobin, K.G. (eds.). International Handbook of Science Education, vol. II, pp. 681-693. Londres: Kluwer Acad. Publisher.

BORKO, H. y PUTNAM, R. (1996). Learning to teach, en Berliner, D. y Calfee, R. (eds.). Handbook of Educational Psychology. Nueva York: Macmillan.

CARNICER, J. et al. (1993). Facilitando el cambio didáctico en la formación permanente del profesorado de ciencias: estudio de casos. Enseñanza de las Ciencias, núm. extra(IV Congreso) pp. 41-42.

CARNICER, J. et al. (1994). El registro de clases en vídeo y su utilización en la investigación educativa. Actas de las VII Jornadas de Experiencias Docentes en Educación Infantil, Primaria y Secundaria, pp. 409-423. Alcañiz: MEC-Gobierno de Aragón y otros.

CARNICER, J. et al. (1997). Relación entre las actividades y los aprendizajes en clase de química, en Aspectos Didácticos de Física y Química (Química), 7, pp. 169-189. Zaragoza: Universidad de Zaragoza.

CARRETERO, M. y LIMÓN M. (1996). Problemas actuales del constructivismo. De la teoría a la práctica, en Rodrigo, M.J. y Arnay (eds.). La construcción del conocimiento escolar. Ecos de un debate Buenos Aires: Auque.

FERNÁNDEZ, I. (2000). «Análisis de las concepciones docentes sobre la actividad científica: una propuesta de transformación». Tesis doctoral. Valencia: Universitat de València.

FURIÓ, C. (1994a). Tendencias actuales en la formación del profesorado de ciencias. Enseñanza de las Ciencias, 12(2), pp. 188-195.

FURIÓ, C.J. (1994b). La enseñanza-aprendizaje de las ciencias como investigación: un modelo emergente, en Science and Mathematics Education for the 21 st. Century: Towards innovatory approaches, vol. I, pp. 159-188. Concepción: Universidad de Concepción. Chile.

FURIÓ, C.J. y GIL, D. (1989). La didáctica de las ciencias en la formación inicial del profesorado: una orientación y un programa teóricamente fundamentados, Enseñanza de las Ciencias, 7(3), pp. 257-265.

FURIÓ, C.J. y GIL, D. (1999). Hacia la formulación de programas eficaces en la formación continuada del profesorado de ciencias, en Sánchez, J.M., Oñorbe, A. y Bustamante, I. (eds.). Educación científica,pp. 129-146. Alcalá de Henares: Servicio de Publicaciones de la Universidad de Alcalá.

GIL, D. (1983). Tres paradigmas básicos en la enseñanza de las ciencias. Enseñanza de las Ciencias, 1(1), pp. 26-33.

GIL, D. (1993). Contribución de la historia y la filosofía de las ciencias al desarrollo de un modelo de enseñanza-aprendizaje como investigación. Enseñanza de las Ciencias, 11(2), pp. 197-212.

GIL, D., CARRASCOSA, J., FURIÓ C. y MARTÍNEZTORREGROSA, J. (1991). La enseñanza de las ciencias en la educación secundaria. Barcelona: Horsori - ICE de la Universidad de Barcelona.

GIL, D., CARRASCOSA, J. y MARTÍNEZ, F.S. (2000). La didáctica de las ciencias: una disciplina emergente y un campo específico de investigación, en Perales, J. y Cañal, P. (eds.). Didáctica de las ciencias: teoría y práctica de la enseñanza de las ciencias. Alcoy: Marfil.

KYLE, W.C., LINN, M.C., BITNER, B.L., MITCHENER, C.P. y PERRY, B. (1991). The role of research in Science Teaching: an NSTA theme paper. Science Education, 75(4), pp. 413-418.

MUNBY,H. y RUSSELL. H. (1998). Epistemology and context in research on learning to teach science, en Fraser, B.J. y Tobin, K.G. (eds.). International Handbook of Science Education, vol. II, pp. 643-665. Londres: Kluwer Acad. Publisher.

PORLÁN, R. (1998). Pasado, presente y futuro de la didáctica de las ciencias. Enseñanza de las Ciencias, 16 (1), pp. 165175 .

PORLÁN, R., RIVERO, A. y MARTÍN, R. (1997). Conocimiento profesional y epistemología de los profesores I: Teoría, métodos e instrumentos. Enseñanza de las Ciencias, 15(2), pp. $155-167$.

SCHÖN, D. A. (1992). La formación de profesionales reflexivos. Paidós. Madrid.

TOBIN, K. y ESPINET, M. (1989). Impediments to change: applications of coaching in high school science teaching. Journal of Research in Science Teaching, 26(2), pp. 105120 .

YOUNGMAN, M.B. (1982). A system for describing teachers' jobs. Educational Studies, 8(1), pp. 23-30.

[Artículo recibido en octubre de 2000 y aceptado en mayo de 2001.] 
ANEXOS

Documento 1. Cuestionario para detectar las concepciones iniciales del profesorado sobre la actividad científica y sobre la enseñanza-aprendizaje de las ciencias

\section{Cuestionario inicial}

La forma de presentar a los alumnos las actividades que llamamos programa de actividades está fundamentada en unas concepciones sobre la ciencia y su enseñanza-aprendizaje que convendría que pusiésemos en común con objeto de utilizar mejor esta herramienta. Para ello puede servirnos este cuestionario.

1. Puesto que el trabajo que nos proponemos es una pequeña investigación, sería conveniente que construyeras un diagrama que contenga los aspectos que consideres más relevantes en un ciclo de investigación científica.

2. ¿Para qué crees que sirve enseñar ciencias en estos niveles?

3. En general, ¿cómo crees que aprende ciencias un alumno?

4. Concretando un poco más, señala las tres dificultades más importantes que crees que van a tener tus alumnos para aprender los contenidos que nos proponemos enseñarles.

5. Para diseñar una unidad didáctica, ¿qué debemos tener en cuenta? ¿Sobre qué deben tratar las primeras actividades que propongamos a nuestros alumnos en ella?

6. a) ¿Cómo han ido evolucionando las ideas sobre los conocimientos que intentamos trabajar?

b) De esas ideas que han habido a lo largo de la historia, ¿cuáles te parecen las más correctas?

c) ¿Qué factores crees que han influido más en la evolución de esas ideas?

7. ¿Qué opinas sobre la siguiente afirmación sacada de conclusiones de investigaciones al respecto?: «La capacidad intelectual de los alumnos es una variable muy relevante en el aprendizaje de las ciencias.»

Documento 2. Cuestionario (final) para extraer información sobre las concepciones del profesorado acerca de la actividad científica y la enseñanza-aprendizaje de las ciencias después de haber participado en el programa de formación

\section{Cuestionario inicial}

1. Si alguien afirmara sobre la ciencia que es un saber que intenta explicar la naturaleza, descubriendo las leyes que la rigen, ¿estarías de acuerdo con él? ¿Por qué?

2. Construye una representación gráfica -a modo de diagrama lo más completo posible- de un ciclo de investigación en el que figuren aquellos aspectos más relevantes que consideres que debe contener un trabajo con aspiración científica.

3. En la unidad didáctica que hemos desarrollado tenemos en cuenta la historia de la ciencia. ¿Para qué? En tu opinión, ¿qué otras funciones se pueden asignar a la historia en la enseñanza de las ciencias?

4. Expresa tu acuerdo o desacuerdo respecto a la siguiente proposición sobre la naturaleza de la ciencia: «El desarrollo de la ciencia a lo largo de la historia ha sido un proceso acumulativo de más y más conocimientos.»

5. ¿Cómo crees que aprende ciencias un alumno/a? ¿En qué medida la vivencia de esta nueva estrategia metodológica ha cambiado tu visión de cómo aprenden los alumnos/as?

6. Con la estrategia metodológica que has practicado, ¿crees que tus alumnos/as han aprendido (más, igual o menos), en la temática enseñada, que con la estrategia que utilizabas anteriormente. ¿Por qué?

7. Señala las dificultades más importantes que han tenido tus alumnos/as para aprender los contenidos que hemos trabajado en la unidad didáctica.

8. Haz una valoración global de tu experiencia respecto a esta manera de enseñar las ciencias (características que te han llamado la atención respecto a: las formas de presentación de las tareas al realizar la clase, funciones principales del profesor, papeles principales de los alumnos/as, relaciones en la clase, cambios en la enseñanza habitual...).

9. Imagina que quieres introducir el concepto de fuerza (en particular el segundo principio de Newton), describe brevemente las fases o etapas de la estrategia metodológica que utilizarías.

10. Señala los cambios que se han producido en tus concepciones (sobre la ciencia, su enseñanza y aprendizaje) y en tus actitudes o comportamiento en tu trabajo de profesor/a. 
Documento 3. Formato de entrevista basado en el cuestionario inicial (documento 1)

Protocolo entrevista

El entrevistador para cada pregunta del cuestionario inicial:

a) pedirá al entrevistado aclaraciones sobre las respuestas dadas a cada pregunta, intentando determinar el sentido de las mismas y utilizando como referencia los criterios de análisis que se muestran en los documentos 3 y 4 del apartado siguiente;

$b$ ) en el caso de que la aclaración dada por el entrevistado sea difícil de valorar con los criterios establecidos, el entrevistador presentará directamente dicho criterio.

Documento 4. Cuestionario de valoración general de las estrategias metodológicas puestas en práctica

Cuestionario de valoración general de las estrategias metodológicas puestas en práctica.

Nos interesa mejorar la metodología que estamos poniendo en práctica en el aula. Para ello vamos a hacer un análisis de la misma y a comparar lo que hacemos ahora con lo que hacíamos antes.

1) Señala las diferencias más relevantes entre lo que estás haciendo ahora en el aula y lo que hacías antes;

a) respecto al diseño de las nuevas estrategias didácticas;

b) respecto a la puesta en acción de las nuevas estrategias metodológicas.

2) Valora las estrategias metodológicas que estamos poniendo en práctica respecto del trabajo de los alumnos y de su aprendizaje. Señala ventajas e inconvenientes de la misma en este aspecto.

3) Valora las estrategias metodológicas que estamos poniendo en práctica respecto al trabajo del profesor y su enseñanza. Señala ventajas e inconvenientes de la misma en este aspecto.

Documento 5. Cuestionario de evaluación final del profesor/a por los alumnos/as

\section{Cuestionario final de evaluación del profesor/a por los alumnos/as}

Las respuestas a este cuestionario nos van a servir para hacer una reflexión sobre el funcionamiento de nuestra clase a lo largo del curso que termina y para mejorar las de próximos cursos, pero, por si consideráramos conveniente matizar algunas respuestas con algunos de vosotros personalmente, utilizaremos un nombre en clave.

Nombre en clave:

El cuestionario consta de 7 apartados. En cada uno de ellos se escriben 6 afirmaciones. Por favor léelas detenidamente antes de responder, luego puntúa de 0 a 10 cada una de ellas según tu acuerdo o desacuerdo con lo que dicen, empleando la siguiente escala:

TA: Totalmente de acuerdo (de 8 a 10)

A: De acuerdo (de 6 a 8 )

I: $\quad$ Indiferente (de 4 a 6$)$

D: $\quad$ En desacuerdo (de 2 a 4 )

TD: Totalmente en desacuerdo (de 0 a 2 )

Después de calificar cada proposición haz una valoración global del apartado y explícala.

\section{LOS CONTENIDOS QUE SE HAN TRABAJADO}

1.1. La cantidad de contenidos ha sido adecuada.

1.2. Los objetivos que se perseguían en los contenidos estaban claros (se sabía para que nos iban a servir).

1.3. Los objetivos perseguidos eran interesantes.

1.4. Los contenidos eran adecuados, en términos de dificultad, para el nivel de edad de los alumnos y alumnas.

1.5. Cuando se introducían nuevos conceptos se relacionaban con los que los alumnos/as conocían anteriormente.

1.6. Los contenidos estaban bien organizados.

Valoración global del apartado 1 


\section{LA FORMA DE TRABAJO EN EL AULA}

2.1. El método de enseñanza fue adecuado a los contenidos.

2.2. En la clase se consiguieron las condiciones necesarias para que los alumnos/as pudieran aprender.

2.3. Las actividades propuestas en clase eran adecuadas para que pudieran ser resueltas por los estudiantes.

2.4. Se hacían puestas en común que han ayudado a clarificar las soluciones a las actividades.

2.5. En el aula había un buen clima de trabajo.

2.6. La forma de trabajo había sido discutida previamente con los alumnos/as hasta llegar a acuerdos....

Valoración global del apartado 2

\section{LA FORMA DE EVALUAR}

3.1. El sistema de evaluación es adecuado.

3.2. El nivel exigido en las evaluaciones se correspondía con el habitual de clase.

3.3. Además de los aprendizajes se han evaluado otros aspectos (trabajo de los alumnos/as, funcionamiento...).

3.4. Además de los exámenes se han utilizado otros instrumentos de evaluación.

3.5. Después de la evaluación se proponían soluciones para corregir las deficiencias observadas.

3.6. El sistema de evaluación había sido discutido previamente con los alumnos/as hasta llegar a acuerdos.

Valoración global del apartado 3

\section{LA FORMA DE CALIFICAR}

4.1. El profesor/a explica la calificación.

4.2. El profesor/a revisa la calificación y la corrige si considera que ha habido error.

4.3. Para calificar, además de los aprendizajes, se han tenido en cuenta los otros aspectos evaluados (trabajo, funcionamiento...)

4.4. En general, los alumnos/as que han aprobado han aprendido.

4.5. Mis calificaciones han sido justas.

4.6. Debería haber más suspensos.

Valoración global del apartado 4

\section{LA APTITUD DEL PROFESOR/A}

5.1. Conoce bien la materia y está al día.

5.2. Sabe enseñar la materia.

5.3. Tiene habilidad para dirigir la actividad de los alumnos/as.

5.4. Presenta las tareas a realizar claramente.

5.5. Consigue que aprendamos por nosotros mismos.

5.6. El profesor/a ha estado pendiente del proceso de aprendizaje de los alumnos/as.

Valoración global del apartado 5

\section{LA ACTITUD DEL PROFESOR/A}

6.1. Tiene en cuenta la opinión de los alumnos/as.

6.2. Respeta a los alumnos/as.

6.3. Es tolerante con los alumnos/as, no se enfada casi nunca.

6.4. Estimula la participación en lo que se estudia. 
6.5. La comunicación del profesor/a con los alumnos/as ha sido fluida.

6.6. Es accesible y está dispuesto a ayudar a los alumnos/as.

Valoración global del apartado 6

\section{LA SATISFACCIÓN CON QUE SE HA TRABAJADO EN CLASE}

7.1. Las clases de esta materia han conseguido atraer mi interés.

7.2. Nunca tengo ganas de que llegue la hora de la clase de esta materia

7.3. Me gusta hacer los trabajos de esta materia aunque no sean obligatorios.

7.4. Creo que debería haber menos horas de clase de esta materia a la semana.

7.5. En las clases ha habido un clima de confianza.

7.6. En las clases ha habido un clima de cooperación.

Valoración global del apartado 7

Documento 6. Criterios para el análisis de visiones deformadas de la ciencia y del trabajo científico

Criterios para el análisis de visiones deformadas de la ciencia y del trabajo científico (c.1.1.)

\section{REPRESENTACIÓN DEL DIAGRAMA DE UN CICLO DE INVESTIGACIÓN}

(Pregunta 1 del cuestionario inicial y del cuestionario de concepciones sobre la ciencia, su enseñanza y aprendizaje).

I.1. Los diagramas comienzan por la observación o experimentación.

I.2. En los diagramas no se hace referencia explícita al planteamiento de problemas como paso fundamental.

I.3. En los diagramas no se hace referencia al cuerpo teórico en el que se plantean los problemas.

I.4. Los diagramas son lineales, no aparecen ramificaciones uniendo los diferentes elementos.

I.5. La mayoría de las flechas que unen los diferentes elementos del diagrama son sólo en un sentido sin vuelta atrás. (En todo caso solamente se considera la revisión de las hipótesis si no han sido validadas en el análisis de resultados).

\section{COMENTARIOS AL DIAGRAMA DE UN CICLO DE INVESTIGACIÓN}

(Entrevista sobre la pregunta 1 del cuestionario inicial y de concepciones, intervenciones en las sesiones).

II.1. Se considera explícitamente la observación como el primer paso de un ciclo de investigación.

II.2. No se considera el planteamiento de un problema en un cuerpo teórico como un paso fundamental en un ciclo de investigación.

II.3. No se concede importancia al cuerpo teórico en el que se realiza la investigación.

II.4. Se describe el ciclo de investigación como una sucesión lineal de pasos.

II.5. No se consideran revisiones de lo realizado o vuelta atrás en la descripción de un ciclo de investigación.

III. CONTESTACIÓN A PREGUNTAS ABIERTAS SOBRE LA CIENCIA, EL TRABAJO CIENTÍFICO Y SU UTILIDAD DIDÁCTICA (PREGUNTA 1 Y 6 DEL CUESTIONARIO INICIAL, ENTREVISTA SOBRE EL MISMO CUESTIONARIO E INTERVENCIONES EN LAS SESIONES)

III.1. Ninguna referencia a los problemas que se plantearon históricamente y cuya solución supuso la construcción del conocimiento.

III.2. Ninguna referencia a crisis y regresiones en la construcción del conocimiento científico, referencia al progreso acumulativo de conocimientos.

III.3. Se valoran como las más correctas las últimas ideas o teorías construidas por la ciencia, considerando las anteriores como erróneas. 
Documento 7. Criterios para el análisis de formas de dar la clase en la que se facilita la participación de los alumnos/as Criterios para el análisis de formas de dar la clase donde se facilita la participación de los alumnos/as DIRECCIÓN DE LA ACTIVIDAD EN CLASE

D’1. Se propone a los estudiantes que se planteen situaciones problemáticas de interés cuyo tratamiento constituirá el hilo conductor del currículo.

D’2. Se da oportunidad para que los estudiantes reflexionen y discutan o debatan entre ellos y entre ellos y el profesor/a.

D’3. Se evalúa continuamente la comprensión de los estudiantes, interviniendo el profesor/a con recapitulaciones, síntesis o reformulaciones oportunas.

\section{ORGANIZACIÓN ESPACIAL Y TEMPORAL DE LA CLASE}

O’1. Habitualmente las mesas se distribuyen en grupos, en círculos, etc.; casi nunca en filas.

O’2. El profesor/a se mueve constantemente por la clase, atendiendo al trabajo en los pequeños grupos y coordinando el debate de los alumnos/as.

O’3. Una pequeña parte del tiempo real de clase se dedica a la presentación de la tarea que se va a realizar.

O’4. Una gran parte del tiempo real de la clase se dedica al trabajo en pequeños grupos sobre la base de actividades propuestas por el profesor/a.

O'5. Otra parte del tiempo se dedica a que los alumnos debatan, moderados por el profesor/a, sobre las diferentes ideas que han surgido en los distintos grupos (interacción entre grupos y entre grupos y profesor/a).

\section{CLIMA DE AULA}

C'1. En las clases se produce un buen número de interacciones entre el profesor/a y los alumnos/as y entre los mismos alumnos/ as.

C'2. Muchas interacciones entre el profesor/a y los alumnos/as a veces surgen como iniciativa de los alumnos/as.

C'3. Las interacciones persiguen la mejor solución en base a argumentos racionales de la situación problemática planteada en la actividad. No se persigue la obtención de recompensas (mejorar la nota, por ejemplo), por lo que no se entra en competición con los demás compañeros/as.

C'4. Cuando el profesor/a llama la atención a los alumnos/as, es para que se pueda mantener un clima adecuado en el que todos puedan aprender, es decir, puedan participar en los debates; por lo tanto, reclamará la atención no sólo para sus aportaciones, sino también para la de los alumnos/as.

Documento 8. Criterios para valorar los posibles cambios producidos en cada profesor

\section{Criterios para el análisis de los cambios producidos}

PREGUNTAS 5, 6 Y 10 DEL CUESTIONARIO FINAL, PREGUNTA 1 DEL CUESTIONARIO SOBRE LA ESTRATEGIA METODOLÓGICA Y ENTREVISTA

EC'1. Autoreferencia al cambio experimentado respecto a las visiones empiristas de la ciencia.

EC'2. Autoreferencias al cambio experimentado en las visiones rígidas de la ciencia.

EC'3. Autoreferencias al cambio experimentado en las relaciones entre aprender y enseñar.

EC'4. Se es consciente de la importancia que tienen las ideas previas del alumno/a como punto de partida del aprendizaje.

EC'5. Se es consciente del cambio experimentado respecto al papel del profesor/a, al pasar de ser un mero transmisor a facilitador o mediador del aprendizaje.

EC'6. Se consideran relevantes, en el aprendizaje de las ciencias, los contenidos procedimentales y actitudinales que antes del programa no se consideraban.

EC'7. Son conscientes de las notables diferencias que hay entre lo que hacen ahora en el aula y lo que hacían antes (valoración de la estrategia metodológica). 
Documento 9. Criterios para valorar las actitudes del profesor/a ante la innovación

Criterios para el análisis de las actitudes ante la innovación

PREGUNTAS 2 Y 3 DEL CUESTIONARIO SOBRE LA ESTRATEGIA METODOLÓGICA, PREGUNTA 4 DEL CUESTIONARIO DE EXPECTATIVAS Y ENTREVISTA

EA1. Cuando se refieran a las ventajas para el alumnado de la puesta en práctica de la innovación, se referirá a que favorece condiciones de aprendizaje como: aumento de la autoconfianza, fomento de la cooperación entre alumnos, implicación en las tareas, autocontrol, amenidad, aumento del interés por la materia, participación en el funcionamiento de la clase.

EA2. Considerarán que sus alumnos aprenden más y mejor por la innovación que están llevando a cabo.

EA3. Señalarán inconvenientes para el alumnado relativos a la puesta en práctica de la innovación, sin cuestionar su validez y proponiendo soluciones, que mejorarían las condiciones de aprendizaje.

EA4. Señalarán su mayor satisfacción con lo que hacen en el aula, al poner en práctica la innovación.

EA5. Los inconvenientes para el profesor que los alumnos señalen no cuestionarán la innovación, achacándolos a su falta de pericia al poner en práctica la innovación.

EA6. Manifestarán su intención de iniciar o continuar su trabajo en el aula de acuerdo con la estrategia metodológica propuesta en la innovación.

EA7. Globalmente valorarán como positiva la experiencia llevada a cabo y señalarán aspectos que pueden mejorarla. 
Tabla I

Resumen del cambio experimentado por cada profesor/a en sus concepciones sobre la ciencia.

\begin{tabular}{|c|c|c|}
\hline PROFESOR/A & $\begin{array}{l}\text { Visiones sobre la ciencia y la actividad científica } \\
\text { antes de participar en el programa }\end{array}$ & $\begin{array}{l}\text { Visiones sobre la ciencia y la actividad científica } \\
\text { después de participar en el programa }\end{array}$ \\
\hline REME & $\begin{array}{l}\text { Racionalista-rígida. - Considera la ciencia } \\
\text { como una construcción humana, } \\
\text { dando importancia al planteamiento } \\
\text { de problemas y a la emisión de hipótesis } \\
\text { dentro de un cuerpo teórico. } \\
\text { - Tiene una visión lineal y rígida de los procesos } \\
\text { y los procedimientos de construcción de la ciencia. }\end{array}$ & $\begin{array}{l}\text { Racionalista-compleja. - Considera la ciencia como una } \\
\text { construcción humana, dando importancia al planteamiento } \\
\text { de problemas y la emisión de hipótesis dentro de un cuerpo } \\
\text { teórico. } \\
\text { - Considera los procesos y procedimientos de construcción } \\
\text { de la ciencia como estrategias generales y complejas, } \\
\text { considerando saltos y regresiones en dichos procesos. }\end{array}$ \\
\hline CHUSA & $\begin{array}{l}\text { - Racionalista-rígida. - Considera la ciencia } \\
\text { como una construcción humana, dando importancia } \\
\text { al planteamiento de problemas y a la emisión de } \\
\text { hipótesis dentro de un cuerpo teórico. } \\
\text { - Tiene una visión lineal y rígida de los procesos } \\
\text { y los procedimientos de construcción de la ciencia. }\end{array}$ & $\begin{array}{l}\text { Racionalista-rígida. - Considera la ciencia como una } \\
\text { construcción humana, dando importancia al planteamiento } \\
\text { de problemas y a la emisión de hipótesis dentro de un } \\
\text { cuerpo teórico. } \\
\text { - Tiene una visión lineal y rígida de los procesos y } \\
\text { procedimientos de construcción de la ciencia, aunque } \\
\text { considera la ciencia en continua construcción. }\end{array}$ \\
\hline PEPE & $\begin{array}{l}\text { - Empirista-rígida. - Atribuye un origen sensorial } \\
\text { al conocimiento científico cercano a posiciones } \\
\text { empiristas. } \\
\text { - Tiene una visión lineal y rígida de los procesos y } \\
\text { los procedimientos de construcción de la ciencia. }\end{array}$ & $\begin{array}{l}\text { Entre racionalista-rígida y racionalista-compleja. } \\
\text {-Considera la ciencia como una construcción humana, } \\
\text { dando importancia al planteamiento de problemas y a la } \\
\text { emisión de hipótesis dentro de un cuerpo teórico. } \\
\text { - Considera complejos los procesos generales de construc- } \\
\text { ción del conocimiento científico y lineal; y rígido, } \\
\text { el método científico. }\end{array}$ \\
\hline VÍCTOR & $\begin{array}{l}\text { - Empirista-rígida. - Atribuye un origen sensorial } \\
\text { al conocimiento científico cercano a posiciones } \\
\text { empiristas. } \\
\text { - Tiene una visión lineal y rígida de los procesos } \\
\text { y los procedimientos de construcción de la ciencia. }\end{array}$ & $\begin{array}{l}\text { Racionalista-compleja. - Considera la ciencia como una } \\
\text { construcción humana, dando importancia al planteamiento } \\
\text { de problemas y a la emisión de hipótesis dentro de un } \\
\text { cuerpo teórico. } \\
\text { - Considera los procesos y procedimientos de construcción } \\
\text { de la ciencia como estrategias generales y complejas, } \\
\text { considerando saltos y regresiones en dichos procesos. }\end{array}$ \\
\hline CLARA & $\begin{array}{l}\text { - Racionalista-compleja. - Considera la ciencia } \\
\text { como una construcción humana, dando importancia } \\
\text { al planteamiento de problemas y a la emisión de } \\
\text { hipótesis dentro de un cuerpo teórico. } \\
\text { - Considera los procesos y los procedimientos de } \\
\text { construcción de la ciencia como estrategias } \\
\text { generales y complejas, considerando } \\
\text { saltos y regresiones en dichos procesos. }\end{array}$ & $\begin{array}{l}\text { Racionalista-compleja. - Considera la ciencia como una } \\
\text { construcción humana, dando importancia al planteamiento } \\
\text { de problemas y a la emisión de hipótesis dentro de un } \\
\text { cuerpo teórico. } \\
\text { - Considera los procesos y procedimientos de construcción } \\
\text { de la ciencia como estrategias generales y complejas, } \\
\text { considerando saltos y regresiones en dichos procesos. }\end{array}$ \\
\hline IGNACIO & $\begin{array}{l}\text { - Empirista-rígida. - Atribuye un origen sensorial } \\
\text { al conocimiento científico cercano a posiciones } \\
\text { empiristas. } \\
\text { - Tiene una visión lineal y rígida de los procesos } \\
\text { y los procedimientos de construcción de la ciencia. }\end{array}$ & $\begin{array}{l}\text { Empirista-rígida. - Atribuye un origen sensorial al } \\
\text { conocimiento científico cercano a posiciones empiristas. } \\
\text { - Tiene una visión lineal y rígida de los procesos y } \\
\text { procedimientos de construcción de la ciencia. }\end{array}$ \\
\hline JAIME & $\begin{array}{l}\text { - Racionalista-rígida. - Considera la ciencia } \\
\text { como una construcción humana, dando importancia } \\
\text { al planteamiento de problemas y la emisión de } \\
\text { hipótesis dentro de un cuerpo teórico. } \\
\text { - Tiene una visión lineal y rígida de los procesos y } \\
\text { los procedimientos de construcción de la ciencia. }\end{array}$ & $\begin{array}{l}\text { Racionalista-rígida. - Considera la ciencia como una } \\
\text { construcción humana, dando importancia al planteamiento } \\
\text { de problemas y a la emisión de hipótesis dentro de un } \\
\text { cuerpo teórico. } \\
\text { - Tiene una visión lineal y rígida de los procesos y } \\
\text { procedimientos de construcción de la ciencia. }\end{array}$ \\
\hline JOSEFA & $\begin{array}{l}\text { - Racionalista-rígida. - Considera la ciencia como } \\
\text { una construcción humana, dando importancia } \\
\text { al planteamiento de problemas y a la emisión } \\
\text { de hipótesis dentro de un cuerpo teórico. } \\
\text { - Tiene una visión lineal y rígida de los procesos } \\
\text { y los procedimientos de construcción de la ciencia. }\end{array}$ & $\begin{array}{l}\text { Racionalista-compleja. - Considera la ciencia como una } \\
\text { construcción humana, dando importancia al planteamiento } \\
\text { de problemas y a la emisión de hipótesis, aunque no } \\
\text { considera el cuerpo de conocimientos. } \\
\text { - Considera los procesos y procedimientos de construcción } \\
\text { de la ciencia como estrategias generales y complejas, } \\
\text { considerando saltos y regresiones en dichos procesos. }\end{array}$ \\
\hline
\end{tabular}




\begin{tabular}{|c|c|c|}
\hline PROFESOR/A & $\begin{array}{l}\text { Concepciones sobre la enseñanza y el } \\
\text { aprendizaje antes de participar en el programa }\end{array}$ & $\begin{array}{c}\text { Concepciones sobre la enseñanza y el aprendizaje } \\
\text { después de participar en el programa }\end{array}$ \\
\hline REME & $\begin{array}{l}\text { Construcción social del conocimiento. } \\
\text { Establece una relación, al menos causal, entre } \\
\text { enseñanza y aprendizaje. Considera las ideas } \\
\text { previas como obstáculos para el aprendizaje. } \\
\text { Concibe la enseñanza como una actividad del } \\
\text { profesor/a para ayudar al alumno/a a aprender. } \\
\text { Reduce el currículo a los contenidos } \\
\text { conceptuales y procedimentales. }\end{array}$ & $\begin{array}{l}\text { Construcción social del conocimiento. Establece una } \\
\text { construcción social del conocimiento. } \\
\text { Establece una relación compleja entre enseñanza } \\
\text { y aprendizaje. Considera las ideas previas como el punto } \\
\text { de partida de nuevos aprendizajes. Concibe la enseñanza } \\
\text { como una actividad del profesor/a para ayudar al alumno/a } \\
\text { a aprender. Considera en el currículo aspectos } \\
\text { conceptuales, procedimentales y actitudinales. }\end{array}$ \\
\hline CHUSA & $\begin{array}{l}\text { Construcción social del conocimiento. } \\
\text { Establece una relación, al menos causal, entre } \\
\text { enseñanza y aprendizaje. Considera las ideas } \\
\text { previas como obstáculos para el aprendizaje. } \\
\text { Concibe la enseñanza como una actividad del } \\
\text { profesor/a para ayudar al alumno/a a aprender. } \\
\text { Reduce el currículo a los contenidos conceptuales. }\end{array}$ & $\begin{array}{l}\text { Construcción social del conocimiento. } \\
\text { Establece una relación compleja entre enseñanza y } \\
\text { aprendizaje. Considera las ideas previas como el punto de } \\
\text { partida de nuevos aprendizajes. Concibe la enseñanza como } \\
\text { una actividad del profesor/a para ayudar al alumno/a a } \\
\text { aprender. Considera en el currículo aspectos conceptuales, } \\
\text { procedimentales y actitudinales }\end{array}$ \\
\hline PEPE & $\begin{array}{l}\text { Construcción social del conocimiento. Establece } \\
\text { una relación compleja entre enseñanza y aprendiza- } \\
\text { je. Considera las ideas previas como el punto de } \\
\text { partida de nuevos aprendizajes. Concibe la } \\
\text { enseñanza como una actividad del profesor/a para } \\
\text { ayudar al alumno/a a aprender. Reduce el currículo } \\
\text { a los contenidos conceptuales y procedimentales. }\end{array}$ & $\begin{array}{l}\text { Construcción social del conocimiento. } \\
\text { Establece una relación compleja entre enseñanza y } \\
\text { aprendizaje. Considera las ideas previas como el punto de } \\
\text { partida de nuevos aprendizajes. Concibe la enseñanza como } \\
\text { una actividad del profesor/a para ayudar al alumno/a a } \\
\text { aprender. Considera en el currículo aspectos conceptuales, } \\
\text { procedimentales y actitudinales }\end{array}$ \\
\hline VÍCTOR & $\begin{array}{l}\text { Transmisión-recepción de conocimientos. } \\
\text { Establece una relación, al menos causal, entre } \\
\text { enseñanza y aprendizaje. No tiene en cuenta las } \\
\text { ideas previas, ni siquiera como obstáculos para } \\
\text { el aprendizaje. Concibe la enseñanza como una } \\
\text { actividad fundamentalmente de transmisión de } \\
\text { conocimientos. Considera en el currículo los } \\
\text { aspectos conceptuales y actitudinales pero no } \\
\text { los procedimentales. }\end{array}$ & $\begin{array}{l}\text { Construcción social del conocimiento. } \\
\text { Establece una relación compleja entre enseñanza } \\
\text { y aprendizaje. Considera las ideas previas como el punto } \\
\text { de partida de nuevos aprendizajes. Concibe la enseñanza } \\
\text { como una actividad del profesor/a para ayudar al alumno/a } \\
\text { a aprender. Considera en el currículo aspectos conceptua- } \\
\text { les, procedimentales y actitudinales }\end{array}$ \\
\hline CLARA & $\begin{array}{l}\text { Transmisión-recepción de conocimientos. No } \\
\text { establece ninguna relación, ni siquiera causal entre } \\
\text { enseñanza y aprendizaje. No tiene en cuenta las } \\
\text { ideas previas, ni siquiera como obstáculos para el } \\
\text { aprendizaje. Concibe la enseñanza como una } \\
\text { actividad fundamentalmente de transmisión de } \\
\text { conocimientos. Considera en el currículo aspectos } \\
\text { conceptuales, procedimentales y actitudinales. }\end{array}$ & $\begin{array}{l}\text { Construcción social del conocimiento. } \\
\text { Establece una relación compleja entre enseñanza y } \\
\text { aprendizaje. Considera las ideas previas como el punto de } \\
\text { partida de nuevos aprendizajes. Concibe la enseñanza como } \\
\text { una actividad del profesor/a para ayudar al alumno/a a } \\
\text { aprender. Considera en el currículo aspectos conceptuales, } \\
\text { procedimentales y actitudinales. }\end{array}$ \\
\hline IGNACIO & $\begin{array}{l}\text { Transmisión-recepción de conocimientos. No } \\
\text { establece ninguna relación, ni siquiera causal entre } \\
\text { enseñanza y aprendizaje. No tiene en cuenta las } \\
\text { ideas previas, ni siquiera como obstáculos para el } \\
\text { aprendizaje. Concibe la enseñanza como una } \\
\text { actividad fundamentalmente de transmisión de } \\
\text { conocimientos. Reduce el currículo a los } \\
\text { contenidos conceptuales. }\end{array}$ & $\begin{array}{l}\text { Transmisión-reccepción de conocimientos. } \\
\text { No establece ninguna relación, ni siquiera causal entre } \\
\text { enseñanza y aprendizaje. No tiene en cuenta las ideas } \\
\text { previas, ni siquiera como obstáculos para el aprendizaje. } \\
\text { Concibe la enseñanza como una actividad fundamental- } \\
\text { mente de transmisión de conocimientos. Reduce el } \\
\text { currículo a los contenidos conceptuales. }\end{array}$ \\
\hline JAIME & $\begin{array}{l}\text { Construcción social del conocimiento. Establece } \\
\text { una relación, al menos causal, entre enseñanza y } \\
\text { aprendizaje. Considera las ideas previas como } \\
\text { obstáculos para el aprendizaje. Concibe la } \\
\text { enseñanza como una actividad del profesor/a para } \\
\text { ayudar al alumno/a a aprender. Reduce el currículo } \\
\text { a los contenidos conceptuales. }\end{array}$ & $\begin{array}{l}\text { Construcción social del conocimiento. } \\
\text { Establece una relación compleja entre enseñanza y } \\
\text { aprendizaje. Considera las ideas previas como el punto de } \\
\text { partida de nuevos aprendizajes. Concibe la enseñanza como } \\
\text { una actividad del profesor/a para ayudar al alumno/a a } \\
\text { aprender. Reduce el currículo a los contenidos conceptuales } \\
\text { y procedimentales. }\end{array}$ \\
\hline JOSEFA & $\begin{array}{l}\text { Construcción social del conocimiento. Establece } \\
\text { una relación, al menos causal, entre enseñanza y } \\
\text { aprendizaje. Considera las ideas previas como } \\
\text { obstáculos para el aprendizaje. Concibe la } \\
\text { enseñanza como una actividad del profesor/a para } \\
\text { ayudar al alumno/a a aprender. Reduce el currículo } \\
\text { a los contenidos conceptuales y procedimentales. }\end{array}$ & $\begin{array}{l}\text { Construcción social del conocimiento. } \\
\text { Establece una relación compleja entre enseñanza } \\
\text { y aprendizaje. Considera las ideas previas como el punto } \\
\text { de partida de nuevos aprendizajes. Concibe la enseñanza } \\
\text { como una actividad del profesor/a para ayudar al alumno/a } \\
\text { a aprender. Considera en el currículo aspectos conceptua- } \\
\text { les, procedimentales y actitudinales. }\end{array}$ \\
\hline
\end{tabular}

